\title{
Apparent diffusion coefficient measurements in the differentiation between benign and malignant lesions: a systematic review
}

\author{
M. A. Vermoolen • T. C. Kwee • R. A. J. Nievelstein
}

Received: 7 December 2011 / Revised: 16 March 2012 / Accepted: 13 April 2012 /Published online: 7 June 2012

(C) The Author(s) 2012. This article is published with open access at Springerlink.com

\begin{abstract}
Objectives To systematically review the value of apparent diffusion coefficient (ADC) measurement in the differentiation between benign and malignant lesions.

Methods A systematic search of the Medline/Pubmed and Embase databases revealed 109 relevant studies. Quality of these articles was assessed using the Quality Assessment of the Studies of Diagnostic Accuracy Included in Systematic Reviews (QUADAS) criteria. Reported ADC values of benign and malignant lesions were compared per organ.

Results The mean quality score of the reviewed articles was $50 \%$. Comparison of ADC values showed marked variation among studies and between benign and malignant lesions in various organs. In several organs, such as breast, liver, and uterus, ADC values discriminated well between benign and malignant lesions. In other organs, such as the salivary glands, thyroid, and pancreas, ADCs were not significantly different between benign and malignant lesions.

Conclusion The potential utility of ADC measurement for the characterisation of tumours differs per organ. Future welldesigned studies are required before ADC measurements can be recommended for the differentiation of benign and malignant lesions. These future studies should use standardised acquisition protocols and provide complete reporting of study methods, to facilitate comparison of results and clinical implementation of ADC measurement for tumour characterisation.
\end{abstract}

Electronic supplementary material The online version of this article (doi:10.1007/s13244-012-0175-y) contains supplementary material, which is available to authorized users.

M. A. Vermoolen $(\triangle) \cdot$ T. C. Kwee $\cdot$ R. A. J. Nievelstein Department of Radiology, University Medical Center,

Heidelberglaan 100 HP. E.01.132, PO Box 85500, 3508 GA,

Utrecht, The Netherlands

e-mail: malouvermoolen@hotmail.com
Keywords Apparent diffusion coefficient · Diffusionweighted imaging $\cdot$ Benign $\cdot$ Malignant $\cdot$ Tumour

\section{Introduction}

Over the past two decades, magnetic resonance (MR) imaging (MRI) has proven to be a valuable diagnostic tool in oncology [1-4]. Rapid improvements in MRI techniques have resulted in MR images with excellent spatial resolution and soft tissue contrast, which contribute to the differentiation of suspected tumours. However, using conventional MRI sequences, difficulty in differentiating benign from malignant lesions may arise when malignant and benign lesions share certain morphologic and contrast-enhancement characteristics. In these cases, diffusion-weighted MR imaging (DWI) might be of value in tumour assessment, as it has the ability to provide tissue contrast based on molecular diffusion [5]. Since the 1990s, DWI using single-shot echo-planar imaging (EPI) has been successfully applied in the field of neuroradiology. It is particularly valuable in the assessment of acute cerebral ischemia [6, 7]. Initially, DWI in other than intracranial sites did not yield sufficient image quality due to susceptibility artefacts and motion artefacts. More recently, technical advances in MRI, such as the development of parallel imaging, high gradient amplitudes, and multichannel coils, have enabled the performance of DWI in the body. These developments have initiated the investigation of applicability of DWI for tumour characterisation, both intra- and extracranially. Diffusionweighted images can be assessed in two ways, qualitatively, by visual assessment of signal intensity, and quantitatively, by measurement of the apparent diffusion coefficient (ADC). The $\mathrm{ADC}$ value quantifies water proton motion, which in biological tissues is a combination of true water diffusion and capillary perfusion. The ADC value can theoretically be used 
to characterise tissues, as the degree of diffusion is correlated to cellular density and extracellular space volume [8, 9]. Malignant tumours are reported to have a high cellular density and low extracellular space volume, which is associated with impeded water proton diffusion and low ADC values. In contrast, various benign lesions are characterised by an increased amount of extracellular matrix with minimal increase of cellular density, which may result in higher ADCs [10, 11]. This hypothesis has been investigated for various types of lesions throughout the body. However, because of the large number of studies on this subject with sometimes conflicting results, the utility of ADC measurements in the characterisation of lesions remains unclear. The aim of this study was therefore to systematically review the current literature on the value of ADC measurement in the differentiation between benign and malignant lesions throughout the entire body.

\section{Materials and methods}

\section{Search strategy}

A systematic literature review was conducted to identify articles on ADC measurements for differentiating benign and malignant lesions (Fig. 1). We performed an electronic search using the Medline/Pubmed and Embase databases. The search string is noted in the flowchart (Fig. 1). No beginning date limit was used and the search was updated until February 25, 2012. No language restriction was applied. Inclusion and exclusion criteria were postulated in consensus by the three authors (M.V./ T.K./R.N.) and were applied to the title/abstract and full text screening (Table 1). One researcher (M.V.) screened the titles and abstracts of the search results and selected 221 eligible

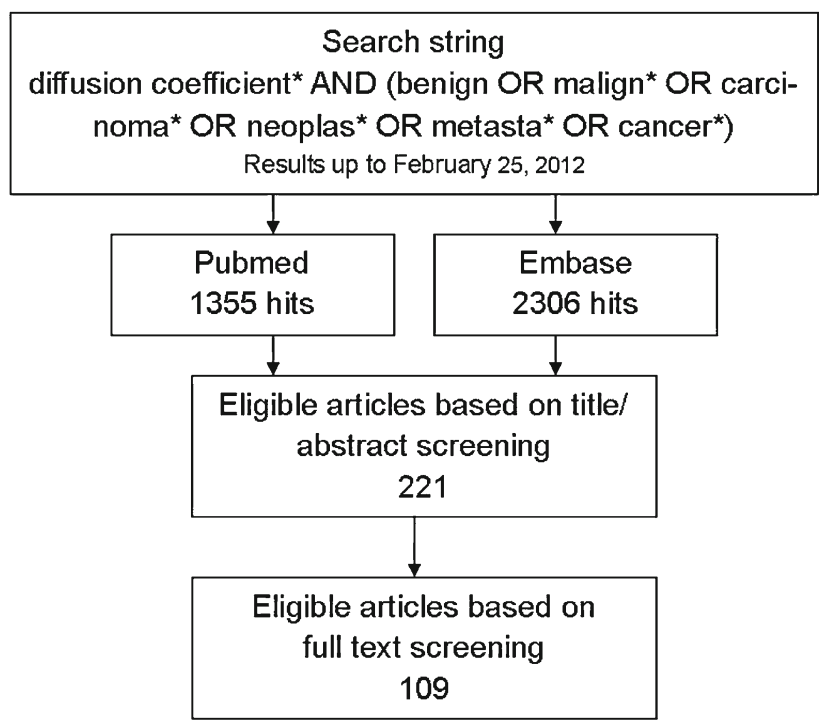

Fig. 1 Flow chart of systematic literature search
Table 1 Inclusion and exclusion criteria

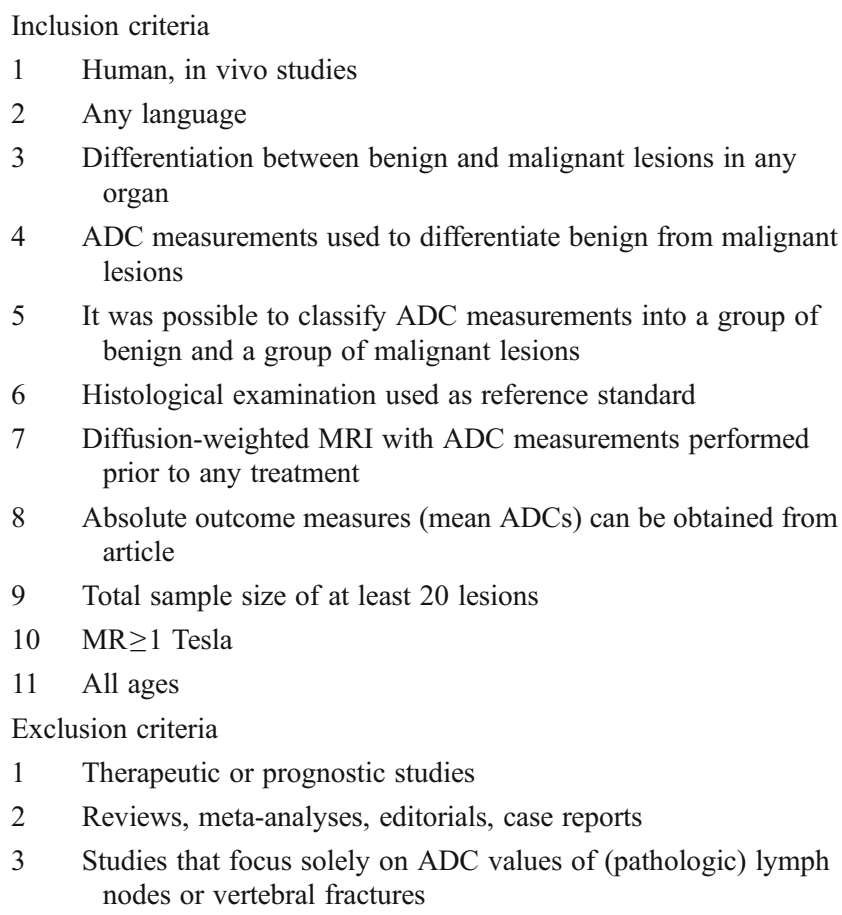

$A D C$ Apparent diffusion coefficient

articles. Full texts were available for 186 of these 221 articles and were screened by one researcher (M.V.). One hundred and nine articles were found to meet the inclusion criteria and were reviewed. The remaining articles were excluded for various reasons, such as lack of histopathological reference standard, the use of ADC ratios instead of true ADC values or describing only the ADC values per histopathological entity, instead of comparing mean ADC values of malignant and benign lesions as a group. Finally, we screened the references of the included articles to find relevant articles that may have been missed in our search, which did not reveal any additional eligible articles. Studies investigating the value of ADC measurements in differentiating benign from malignant prostatic lesions were excluded, because the most important clinical role of DWI with ADC mapping in the prostate is cancer detection and characterisation. In addition, we did not review studies on differentiation of malignant and benign lymphadenopathy, as this subject lies beyond the scope of this paper.

Quality assessment

All relevant papers were assessed for quality using the Quality Assessment of the Studies of Diagnostic Accuracy Included in Systematic Reviews (QUADAS) criteria [12]. We modified this 14-item instrument for optimum applicability to this review. The complete list of criteria is presented in Table 2. One reader (M.V.) assigned positive or negative scores to these 
Table 2 Adjusted QUADAS ${ }^{\mathrm{a}}$ tool for quality assessment

Quality item
1. Was the spectrum of patients
representative of the patients
who will receive the test in
practice?
2. Were selection criteria clearly
described?
3. Is the reference standard likely
to correctly classify the target
condition?
4. Was the time period between
histological assessment and
DWI short enough to be
reasonably sure that the target
condition did not change
between the two tests?
5. Did the whole sample or a
random selection of the sample
receive verification using a
reference standard of
diagnosis?
6. Did patients receive the same
reference standard regardless of
the index test result?
7. Was the execution of the index
test described in sufficient
detail to permit replication of
the test?

8. Was the execution of the reference test described in sufficient detail to permit replication?

9. Were the index test results interpreted without knowledge of the results of the reference standard?

10. Were the reference standard results interpreted without knowledge of the results of the index test?

11. Were the same clinical data available when test results were interpreted as would be

available when the test is used in practice?

12. Were withdrawals from the study explained?

Positive score

Patients with lesions detected at conventional imaging (e.g., CT, US, or anatomical MRI).

Conventional imaging could not assess whether those lesions were benign or malignant

It was clear how patients were selected for inclusion

Histological examination was used as a reference standard

Histological assessment was performed within 2 weeks after DWI

All patients, or a random sample of patients, received histological examination

Patients received histological assessment regardless of ADC measured

All of the following MRI parameters are described: field strength, coil type, sequence type, applied $b$-values, BH/RT/ $\mathrm{FB}$, and direction(s) of applied diffusion gradients

Description of the following points: means of harvesting histological material (biopsy or surgery) given, interpreter of histological assessment mentioned

DWI was interpreted without knowledge of the histological assessment findings

Histological assessment was interpreted without knowledge of the DWI findings

Clinical data were available to the interpreter(s) of the DWI

Withdrawals from the study after inclusion were explained

$D W I$ Diffusion-weighted imaging, $A D C$ apparent diffusion coefficient, $B H$ breath-hold, $R T$ respiratory triggering, $F B$ free breathing

${ }^{\text {a }}$ Adapted from [12]

criteria for all of the eligible articles. If insufficient information was provided the item was given a negative score. Total quality scores were expressed as a percentage of the maximum score. Quality scores of $0-39 \%$ were rated as poor, $40-70 \%$ as moderate, and $70-100 \%$ as good.

\section{Data presentation}

Reported ADC values of the reviewed studies are presented per organ or body region. The reported ADC values (mean \pm standard deviation) of benign and malignant tumours in each organ will be discussed and compared and are represented graphically in the accompanying figures. We did not perform meta-analyses as the substantial variation in study characteristics and applied diffusion-weighted imaging parameters of the reviewed studies prevented meaningful pooling of the data. We aimed to give a broad overview of the literature on differentiation between benign and malignant tumours.

\section{Results}

We identified 109 articles that described and compared mean ADC values for malignant and benign tumours in various body regions, of which 14 were intracranial and 95 extracranial. The included extracranial regions were salivary glands (6), thyroid (6), breast (24), lung (2), liver (14), gallbladder (1), pancreas (9), kidney (8), adrenal gland (4), uterus (8), ovaries (7), and soft tissue (6). Study design was prospective in 38 studies, retrospective in 39 , and unreported in 32 out of 109 studies. Most studies (98 out of 109) used echo planar imaging (EPI) pulse sequences for diffusion-weighted imaging, and 64 out of 109 studies reported using diffusion gradients in three orthogonal directions (along the $x, y$, and $z$ axes).

Study quality

Quality assessment was performed by assessing quality scores for all studies, using 12 criteria adapted from the QUADAS tool [12]. Total quality scores in the included studies ranged from 25 to $75 \%$. The average score of all studies was $50 \%$, which is moderate, but indicates that these studies may have important limitations. In the quality assessment of these studies many negative scores were appointed because important details of study design were not reported (Fig. 2). In most studies, the patient sample was representative of the clinical setting in which DWI and ADC measurements are applied. The methods of patient enrolment were sufficiently described (in $97 \%$ of studies), and in many studies histopathological verification was available. However, in $38 \%$ of studies, histological diagnosis was not available for all lesions included in the analyses. Although in common practice it is not feasible to obtain histological 


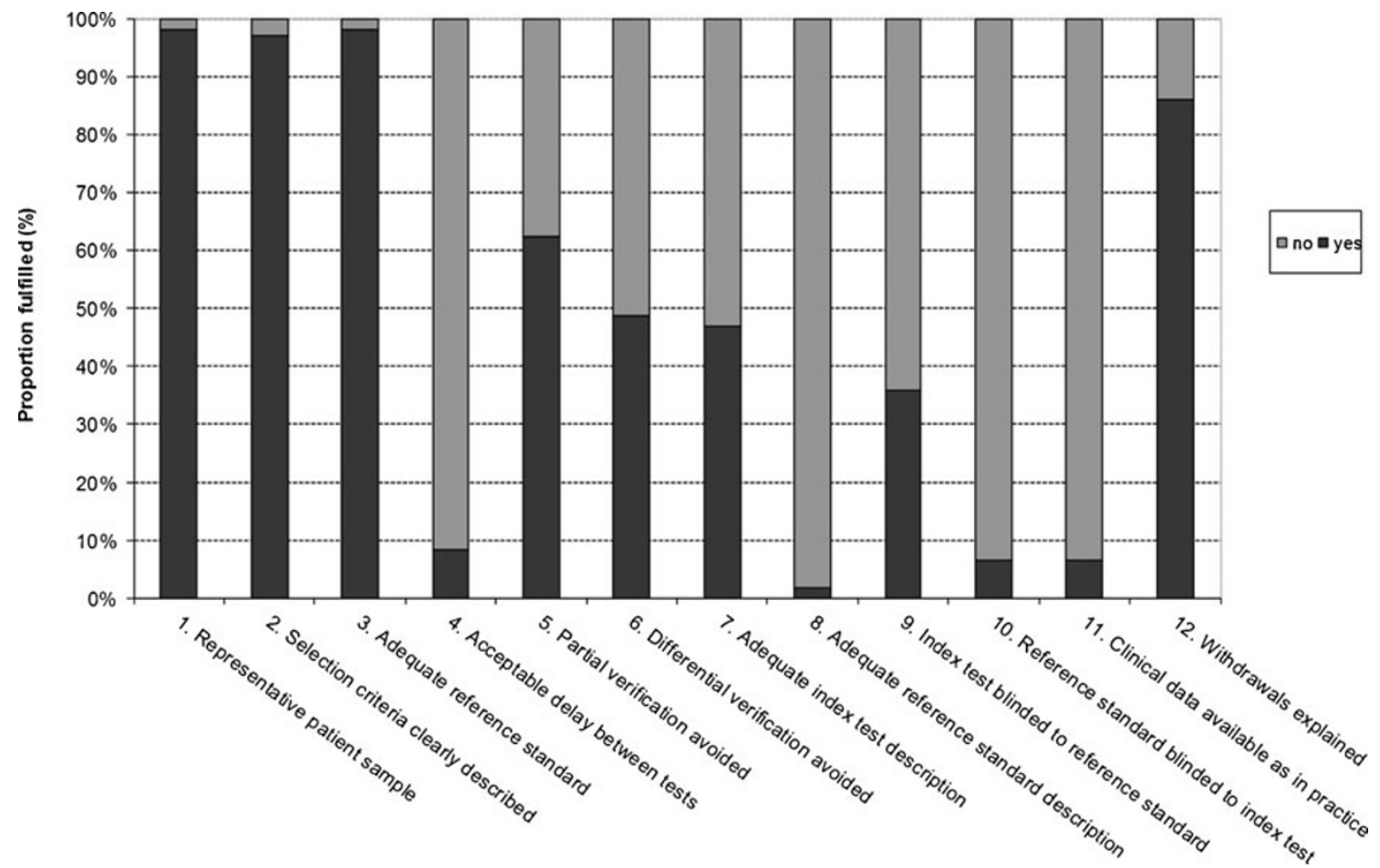

Fig. 2 Overall quality assessment of all 109 included studies. Data are presented as stacked bars for each quality item of the modified Quality Assessment of the Studies of Diagnostic Accuracy Included in Systematic Reviews (QUADAS) tool

verification of all (benign and malignant) lesions, and a reasonable reference standard is provided by follow-up of these lesions, partial verification bias may not be fully excluded. Reporting on methods of diffusion-weighted imaging and ADC measurement was not sufficient in a substantial fraction of the studies (53\% of studies), although these data are important for the comparison of ADC measurements among studies. Furthermore, authors frequently failed to document whether blinding was used for the assessment of the index test (64\% of studies) and reference test ( $94 \%$ of studies).

In the following section, a summary of the results will be presented per organ or body region. Due to the large number of studies reviewed, tables containing study characteristics could not be included in this paper but are provided in the Electronic Supplementary Material (ESM S1-S14).

\section{Intracranial}

The articles regarding intracranial DWI addressed the following issues: differential diagnosis between cerebral abscesses and necrotic or cystic malignant tumours and between typical (benign) and atypical (malignant) meningiomas. Differentiation of high- and low-grade malignant brain tumours has also been studied extensively but lies beyond the scope of this review and will not be discussed.

We identified eight articles that compared mean ADC values of abscesses to malignant cerebral tumours with a cystic or necrotic component (ESM Table S1) [13-20]. Malignant lesions included in these studies were predominantly high-grade gliomas and metastases and a smaller number of low-grade gliomas and cerebral lymphomas. Quality scores of these articles were low to moderate, ranging from 25 to $50 \%$. The studied populations ranged from 18 to 54 patients. Applied maximum $b$-values ranged from 972 to $1,200 \mathrm{~s} / \mathrm{mm}^{2}$. All studies measured ADC values with placement of a region of interest (ROI) in the cystic component of abscesses and malignant tumours. These studies found that overall, cerebral abscesses show restricted diffusion with hyperintensity on DWI and low ADC values. Lowest reported mean ADC of abscesses was $0.42 \pm 0.15 \times$ $10^{-3} \mathrm{~mm}^{2} / \mathrm{s}$ and the highest reported mean ADC in these studies was $0.94 \pm 0.42 \times 10^{-3} \mathrm{~mm}^{2} / \mathrm{s}$. For malignant lesions, reported mean ADC values ranged from $1.45 \pm 0.67$ to $2.96 \times 10^{-3} \mathrm{~mm}^{2} / \mathrm{s}$ (Fig. 3). Three authors reported a significant difference between ADC values of cerebral abscesses and malignant tumours [15, 16, 19]; the other authors did not provide $P$-values.

Six articles discussed the contribution of DWI to the differentiation between histologic grades of meningiomas (ESM Table S2) [21-26]. Quality scores ranged from 42 to $67 \%$. DWI was performed on a $1.0 \mathrm{~T}$ MR system in one study, $1.5 \mathrm{~T}$ in four studies, and $3.0 \mathrm{~T}$ in one study [26], and all authors applied a high maximum $b$-value of $800-1,000 \mathrm{~s} / \mathrm{mm}^{2}$. All except one of the studies showed lower ADC values in atypical and 


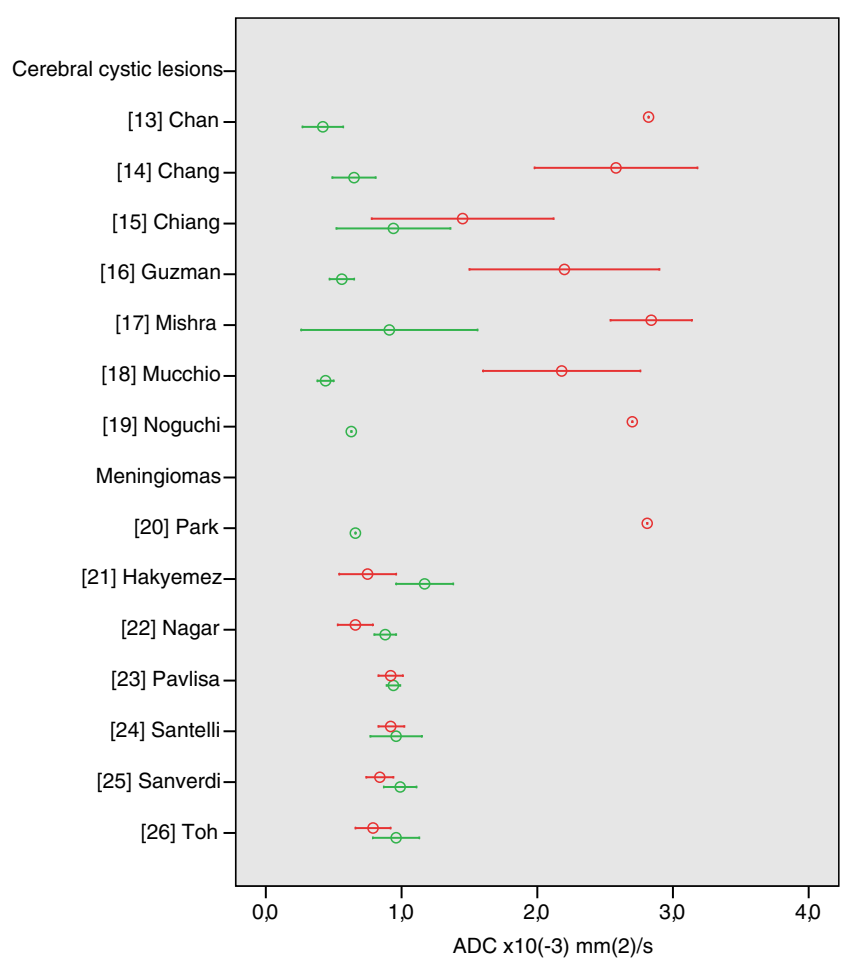

Fig. 3 Apparent diffusion coefficient (ADC) values of intracranial lesions. Reported mean (circles) $\mathrm{ADC} \pm 1 \mathrm{SD}$ (whiskers) of cerebral cystic tumours (red) vs. cerebral abscesses (green) and malignant (red) vs. benign (green) meningiomas

malignant meningiomas than in typical meningiomas, with $P$-values $<0.05$ in three out of six studies [21, 22, 26]. However, considerable overlap existed between the types of meningiomas. Mean ADC values of typical meningiomas ranged from $0.88 \pm 0.08$ to $1.17 \pm 0.21 \times$ $10^{-3} \mathrm{~mm}^{2} / \mathrm{s}$, mean ADC values of atypical and malignant meningiomas ranged from $0.66 \pm 0.13$ to $0.923 \pm$ $0.085 \times 10^{-3} \mathrm{~mm}^{2} / \mathrm{s}$ (Fig. 3).

\section{Salivary glands}

We identified six articles that compared mean ADCs of pleomorphic adenomas, Warthin tumours, and salivary gland carcinomas (ESM Table S3) [27-32]. Two studies $[29,30]$ included lesions in all major salivary glands, four studies included only parotid gland lesions. The studies had moderate quality scores, ranging from 50 to $58 \%$. All studies used a high maximum $b$-value of $1,000 \mathrm{~s} /$ $\mathrm{mm}^{2}$. Five authors $[27,29,31-32]$ showed that pleomorphic adenomas have high mean ADC values, ranging from $1.54 \pm 0.35$ to $2.09 \pm 0.16 \times 10^{-3} \mathrm{~mm}^{2} / \mathrm{s}$, compared to malignant tumours, which had mean ADC values ranging from $0.79 \pm 0.33$ to $1.40 \pm 0.39 \times$ $10^{-3} \mathrm{~mm}^{2} / \mathrm{s}$ (Fig. 4). This difference was significant in two out of five studies $[25,28]$. The benign Warthin tumours were observed to have low mean ADC values,

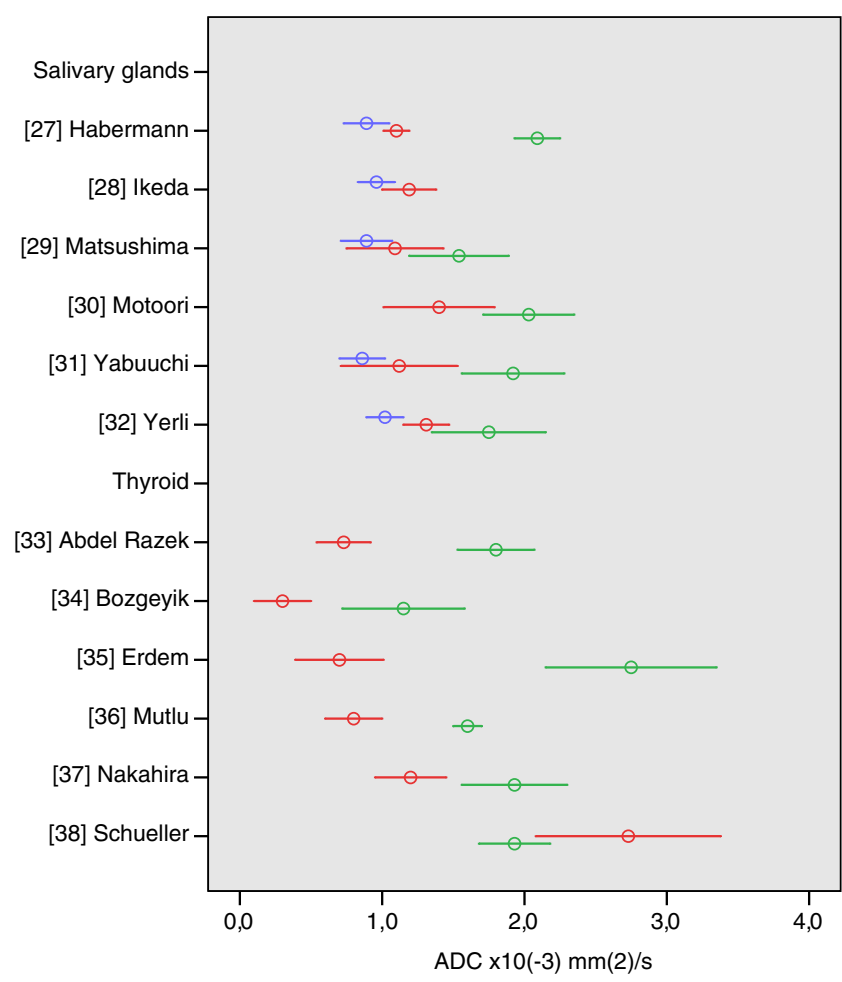

Fig. 4 Apparent diffusion coefficient (ADC) values of salivary gland and thyroid lesions. Reported mean (circles) $\mathrm{ADC} \pm 1 \mathrm{SD}$ (whiskers) of malignant (red) vs. benign (green) thyroid tumours. Salivary gland malignant tumours (red) vs. pleomorphic adenomas (green) vs. Warthin tumours (blue)

ranging between $0.89 \pm 0.16$ and $1.02 \pm 0.13 \times 10^{-3} \mathrm{~mm}^{2} / \mathrm{s}$, comparable to the ADC values of malignant tumours.

\section{Thyroid}

Six studies addressed the issue of differentiating benign and malignant thyroid nodules with DWI and ADC measurement (ESM Table S4) [33-38]. Quality scores of these studies ranged from 25 to $75 \%$. Applied maximum $b$-values were 300 [34], 500 [33], 800 [38], and 1,000 [35-37]. All authors measured ADC values in solid (components of) lesions. The six included studies showed a marked variance in ADC values of thyroid nodules. In five studies [33-37], ADC values of thyroid carcinoma were significantly lower than ADC values of benign thyroid nodules. In these studies, mean ADC values of benign nodules ranged from $1.15 \pm 0.43$ to $2.75 \pm$ $0.60 \times 10^{-3} \mathrm{~mm}^{2} / \mathrm{s}$, mean ADC values of malignant lesions ranged from $0.30 \pm 0.20$ to $1.20 \pm 0.25 \times 10^{-3} \mathrm{~mm}^{2} / \mathrm{s}$ (Fig. 4). However, one study [38] found a remarkably high mean ADC value in 16 thyroid carcinomas $(2.73 \pm$ $0.65 \times 10^{-3} \mathrm{~mm}^{2} / \mathrm{s}$ ), which was significantly higher than the mean ADC of benign thyroid adenomas (1.93 \pm $0.25 \times 10^{-3} \mathrm{~mm}^{2} / \mathrm{s}$ ). 
Breast

We identified 24 articles on the differentiation of breast lesions with ADC measurement (ESM Table S5) [39-62]. Quality scores ranged from 33 to $67 \%$. The number of lesions included in the studies ranged from 22 to 262 . Most studies applied high $b$-values of $1,000 \mathrm{~s} / \mathrm{mm}^{2}$ (15 out of 24) or $1,500 \mathrm{~s} / \mathrm{mm}^{2}$ (4 out of 24). Twenty studies showed statistically significant differences between ADC values of benign and malignant breast lesions. Among studies using maximum $b$-values of 700 or higher, mean ADC values of benign lesions ranged from 1.19 to $1.73 \pm 0.34 \times 10^{-3} \mathrm{~mm}^{2} / \mathrm{s}$, whereas mean ADC values of malignant lesions ranged from 0.73 to $1.22 \pm 0.31 \times$ $10^{-3} \mathrm{~mm}^{2} / \mathrm{s}$ (Fig. 5). Higher mean ADC values were observed

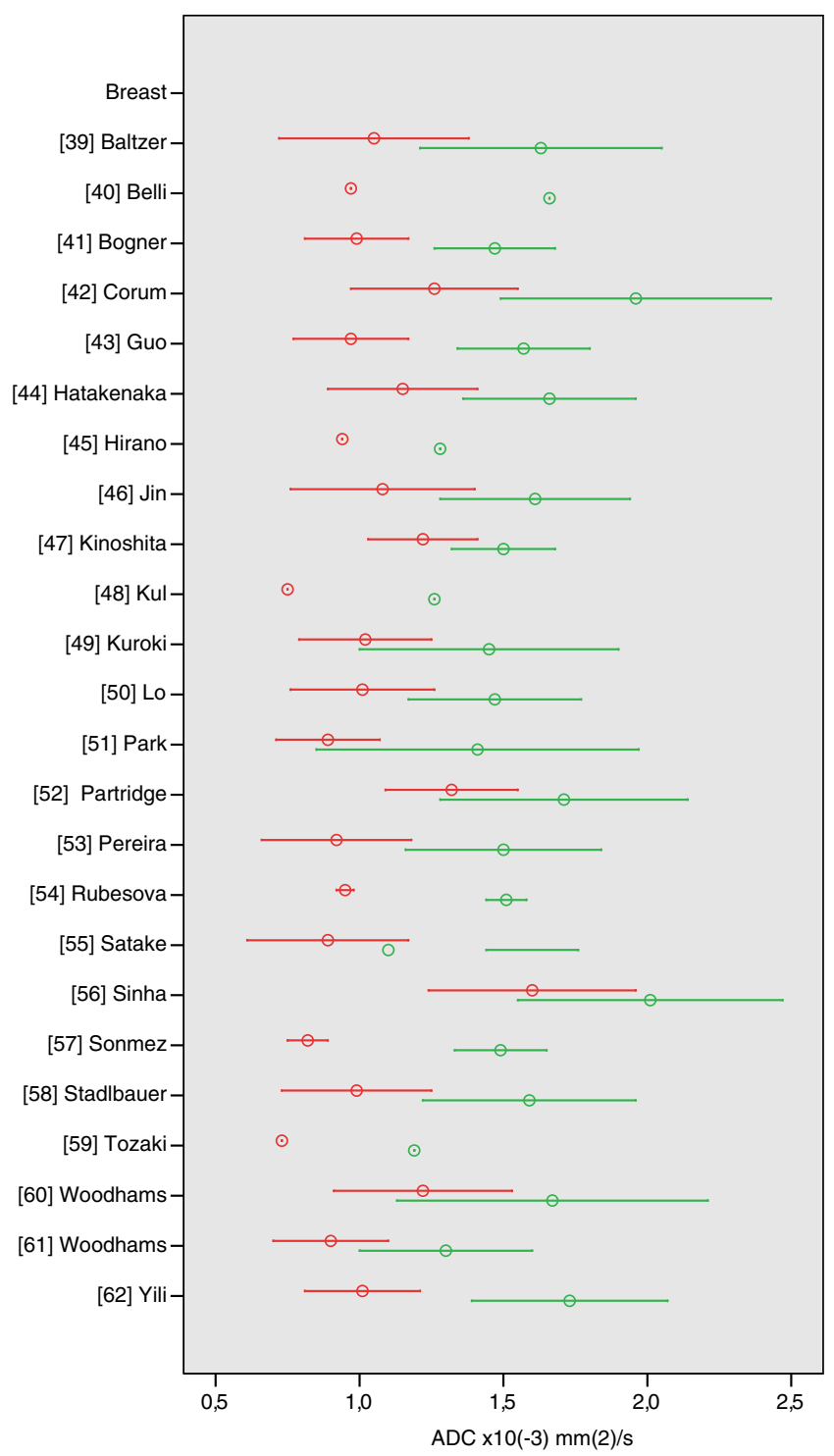

Fig. 5 Apparent diffusion coefficient (ADC) values of breast lesions. Reported mean (circles) $\mathrm{ADC} \pm \mathrm{SD}$ (whiskers) of malignant (red) vs. benign (green) tumours in three studies that applied lower $b$-values (maximum 290$600 \mathrm{~s} / \mathrm{mm}^{2}$ ), for both benign (range $1.71 \pm 0.43$ to $2.01 \pm 0.46 \times$ $10^{-3} \mathrm{~mm}^{2} / \mathrm{s}$ ) and malignant breast lesions (range $1.26 \pm 0.29$ to $\left.1.60 \pm 0.36 \times 10^{-3} \mathrm{~mm}^{2} / \mathrm{s}\right)[42,52,56]$.

Lung

The systematic search revealed two studies on the ability of ADC values to discriminate between benign and malignant lung lesions (ESM Table S6). Uto et al. [63] studied 28 patients with pulmonary nodules, using $b$-values of 0 and $1,000 \mathrm{~s} / \mathrm{mm}^{2}$. Quality score of this study was $67 \%$. The calculated mean ADC for benign (inflammatory) nodules was $1.15 \pm 0.31 \times 10^{-3} \mathrm{~mm}^{2} / \mathrm{s}$, and mean ADC for lung cancer was $1.02 \pm 0.36 \times 10^{-3} \mathrm{~mm}^{2} / \mathrm{s}$ (Fig. 6). There was no significant difference between benign pulmonary lesions and lung cancer $(P=0.388)$. A second study on ADC values in pulmonary nodules by Liu et al. [64], however, did show a significant difference between benign (inflammatory and noninflammatory) nodules and malignant nodules $(P=0.001)$. Mean ADC value of benign lesions was $1.65 \pm 0.42$, while malignant nodules had a mean ADC of $1.26 \pm 0.32 \times 10^{-3} \mathrm{~mm}^{2} / \mathrm{s}$. The applied maximum $b$-value in this study was $500 \mathrm{~s} / \mathrm{mm}^{2}$.

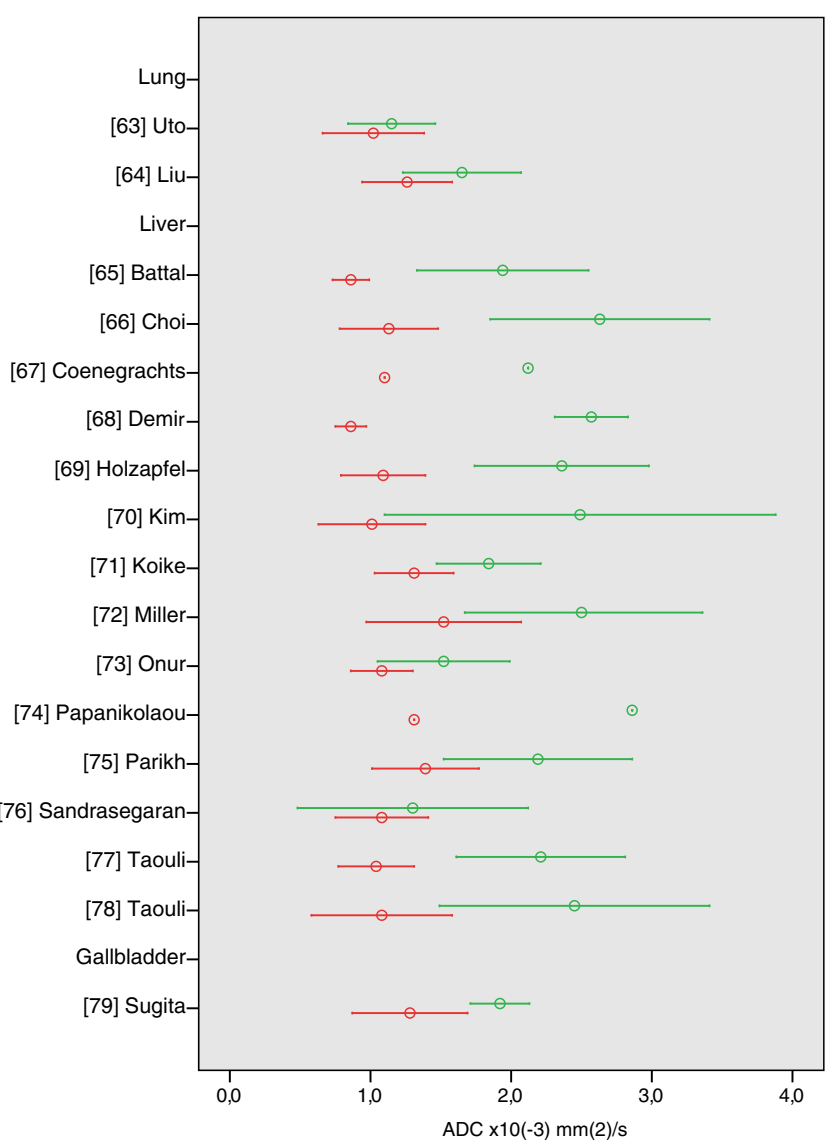

Fig. 6 Apparent diffusion coefficient (ADC) values of lung, liver, gallbladder. Reported mean (circles) $\mathrm{ADC} \pm \mathrm{SD}$ (whiskers) of malignant (red) vs. benign (green) tumours 


\section{Liver}

Fourteen studies described ADC values of benign and malignant liver lesions (ESM Table S7) [65-78]. Quality scores ranged from 25 to $58 \%$. All of these studies used single-shot EPI diffusion-weighted sequences. Seven studies applied maximum $b$-values of $400-600 \mathrm{~s} / \mathrm{mm}^{2}$, while the other half of the studies applied maximum $b$-values of $800-1,000 \mathrm{~s} / \mathrm{mm}^{2}$. Mean $\mathrm{ADC}$ values of benign hepatic lesions were higher than those of malignant lesions in all studies, of which 11 studies showed a statistically significant difference [65-70, 72-75, 78]. Mean $\mathrm{ADC}$ values of benign liver lesions ranged from 1.94 to $2.86 \times$ $10^{-3} \mathrm{~mm}^{2} / \mathrm{s}$, mean ADC values of malignant tumours ranged from $0.86 \pm 0.11$ to $1.52 \pm 0.55 \times 10^{-3} \mathrm{~mm}^{2} / \mathrm{s}$ (Fig. 6). In all but two of these studies, benign cysts were included in the group of benign lesions.

\section{Gallbladder}

We identified only one article in which the differentiation of benign and malignant gallbladder lesions with ADC measurement is described (ESM Table S8). Sugita et al. [79] retrospectively studied ADC values of 14 benign and 15 malignant gallbladder lesions, with $b$ values of 0 and $1,000 \mathrm{~s} / \mathrm{mm}^{2}$. Quality score of this study was $50 \%$. Mean ADC of benign lesions was $1.92 \pm 0.21 \times$ $10^{-3} \mathrm{~mm}^{2} / \mathrm{s}$, mean ADC of malignant lesions was $1.28 \pm$ $0.41 \times 10^{-3} \mathrm{~mm}^{2} / \mathrm{s}$; the difference was statistically significant $(P<0.01)$ (Fig. 6).

\section{Pancreas}

Several studies have been published on the differentiation of pancreatic cystic lesions with diffusion-weighted imaging and ADC measurement (ESM Table S9) [80-88]. Quality scores in these studies ranged from 33 to $58 \%$. Five studies compared ADC values of benign mass-forming pancreatitis with ADC values of pancreatic cancer, and two studies did not specify the histological types of the investigated benign and malignant pancreatic lesions. These five studies on ADC measurement in pancreatic lesions show inconsistent results. Lee et al. [85] and Takeuchi et al. [87] found significantly lower mean ADC values in benign than in malignant pancreatic lesions, $1.04 \pm 0.18$ vs. $1.23 \pm 0.18 \times 10^{-3} \mathrm{~mm}^{2} / \mathrm{s}$ and $1.00 \pm 0.18$ vs. $1.38 \pm 0.38 \times 10^{-3} \mathrm{~mm}^{2} / \mathrm{s}$, respectively (Fig. 7). Fattahi et al. [80] and Kartalis et al. [83] measured significantly higher mean ADC values in benign than in malignant lesions, $2.09 \pm 0.18$ and $2.57 \pm 1.17 \times 10^{-3} \mathrm{~mm}^{2} / \mathrm{s}$ versus $1.46 \pm 0.18$ and $1.40 \pm 0.30 \times 10^{-3} \mathrm{~mm}^{2} / \mathrm{s}$, respectively. Yamashita et al. [88] also found mean ADC values of benign tumours $\left(3.2 \pm 1.3 \times 10^{-3} \mathrm{~mm}^{2} / \mathrm{s}\right)$ to be higher than those of malignant tumours $\left(2.7 \pm 0.9 \times 10^{-3} \mathrm{~mm}^{2} / \mathrm{s}\right)$, however, this was not statistically significant. ADC values measured by

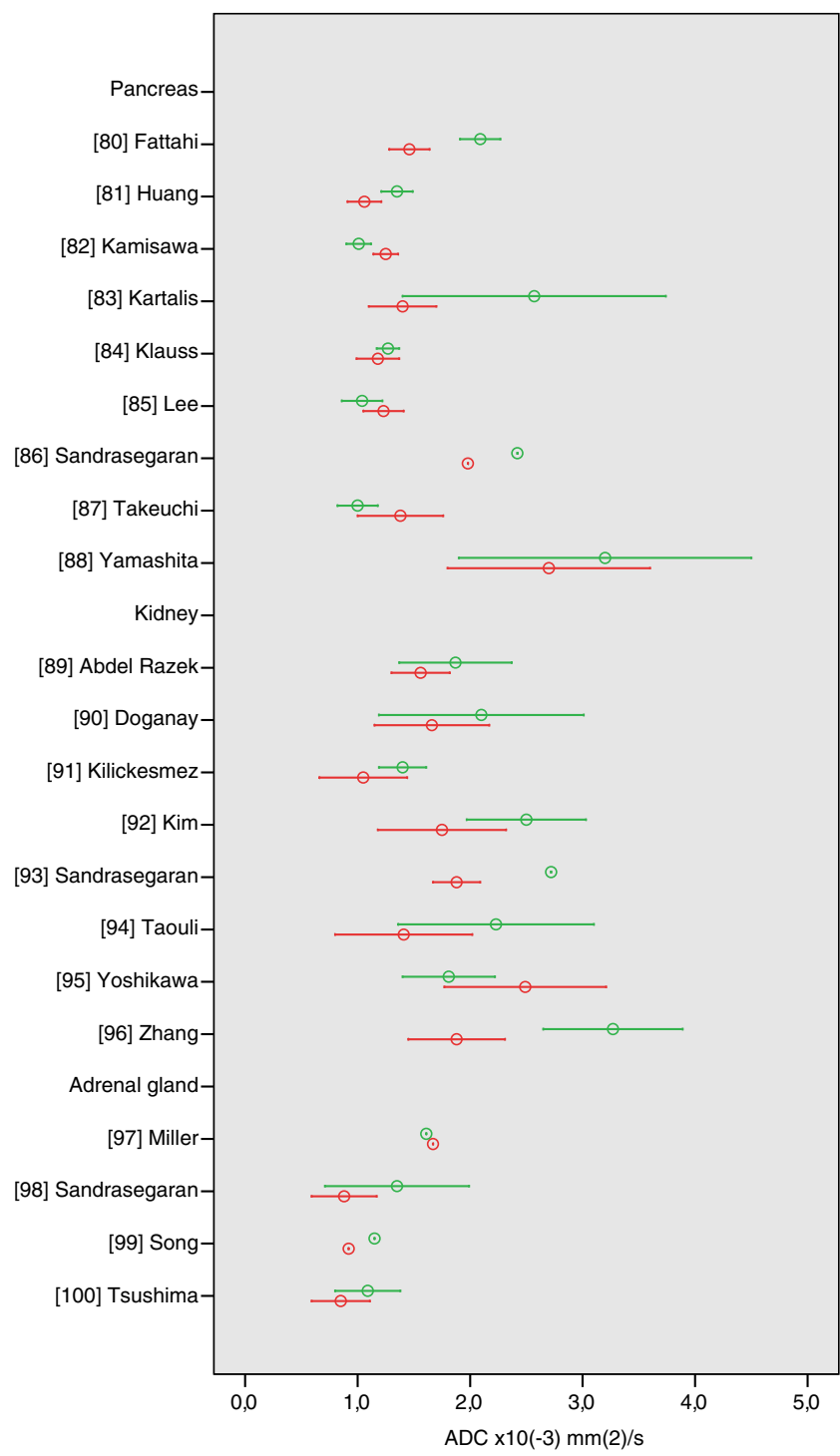

Fig. 7 Apparent diffusion coefficient (ADC) values of pancreas, kidney, and adrenal gland lesions. Reported mean (circles) $\mathrm{ADC} \pm \mathrm{SD}$ (whiskers) of malignant (red) vs. benign (green) tumours

Yamashita et al. with relatively low $b$-values 0 and $300 \mathrm{~s} / \mathrm{mm}^{2}$ were higher than the ADC values in the other studies.

\section{Kidney}

$\mathrm{ADC}$ values of kidney tumours were described in six retrospective studies and two prospective studies (ESM Table S10) [89-96]. Quality scores of these studies ranged from 42 to $67 \%$. Applied maximum $b$-values ranged from 400 to $1,000 \mathrm{~s} / \mathrm{mm}^{2}$. All studies included benign renal cysts and seven out of eight studies showed significant differences between benign and malignant renal lesions. Lowest mean ADC values of benign lesions were reported for angiomyolipomas (1.40 to $1.81 \times 10^{-3} \mathrm{~mm}^{2} / \mathrm{s}$ ), and highest mean ADC values of benign lesions were reported for simple cysts $\left(2.50\right.$ to $3.82 \times 10^{-3} \mathrm{~mm}^{2} /$ 
s). Mean ADC values of malignant renal lesions (mainly renal cell carcinomas) ranged from 1.05 to $2.49 \times 10^{-3} \mathrm{~mm}^{2} / \mathrm{s}$ (Fig. 7).

\section{Adrenal gland}

We found four studies that described ADC values of adrenal gland lesions (ESM Table S11). These studies had quality scores of 33-50\% and applied high maximum $b$-values of 800-1,000 s/mm ${ }^{2}$. Sandrasegaran et al. [98] and Song et al. [99] evaluated benign pheochromocytomas and adenomas, which were reported to have significantly higher ADC values than malignant (metastatic) adrenal lesions (1.07 to $1.35 \times 10^{-3} \mathrm{~mm}^{2} / \mathrm{s}$ versus 0.88 to $0.92 \times 10^{-3} \mathrm{~mm}^{2} / \mathrm{s}$, respectively). However, a larger study by Miller et al. [97] did not show a significant difference between benign and malignant adrenal gland lesions. Tsushima et al. [100] could only confirm a significant difference between adenomas and malignant pheochromocytomas, but not between adrenal adenomas and metastases (Fig. 7).

\section{Uterus}

Eight studies have been published in which the differentiation between benign and malignant uterine tumours using ADC measurement was investigated (ESM Table S12) [101-108]. Quality scores of these studies ranged from 33 to $67 \%$. All eight studies used high $b$-values (maximum 800-1,000 $\mathrm{s} / \mathrm{mm}^{2}$ ) for diffusion-weighted imaging and showed comparable ADC values for uterine lesions. Benign lesions included in these studies were mainly leiomyomas, and the malignant lesions included were mainly endometrial carcinomas in five studies [101-103, 105, 108] and sarcomas in the other three studies [104, 106, 107]. Benign lesions had significantly higher mean ADC values (range $1.18 \pm 0.24$ to $1.64 \pm 0.18 \times 10^{-3} \mathrm{~mm}^{2} / \mathrm{s}$ ) than malignant lesions (range $0.76 \pm 0.26$ to $1.17 \pm 0.15 \times 10^{-3} \mathrm{~mm}^{2} / \mathrm{s}$ ) in seven out of eight studies (Fig. 8).

\section{Ovaries}

Seven articles retrieved in our search studied ADC values in ovarian tumours (ESM Table S13) [103, 109-114]. Quality scores ranged from 50 to $67 \%$. Applied maximum $b$-value was $1,000 \mathrm{~s} / \mathrm{mm}^{2}$ in four studies, and $500-800 \mathrm{~s} / \mathrm{mm}^{2}$ in three studies. In two studies, ADC values were measured in regions of interest placed in the cystic components of ovarian lesions [110, 112], two studies measured ADC values of solid components [109, 113] and three studies measured ADC values of both cystic and solid components [103, 111, 114]. Mean ADC values of cystic components of benign ovarian lesions ranged from $1.24 \pm 0.46$ to $2.32 \pm$ $0.56 \times 10^{-3} \mathrm{~mm}^{2} / \mathrm{s}$, mean ADC values of cystic components of malignant lesions ranged from $1.64 \pm 0.48$ to $2.34 \pm 0.47 \times$

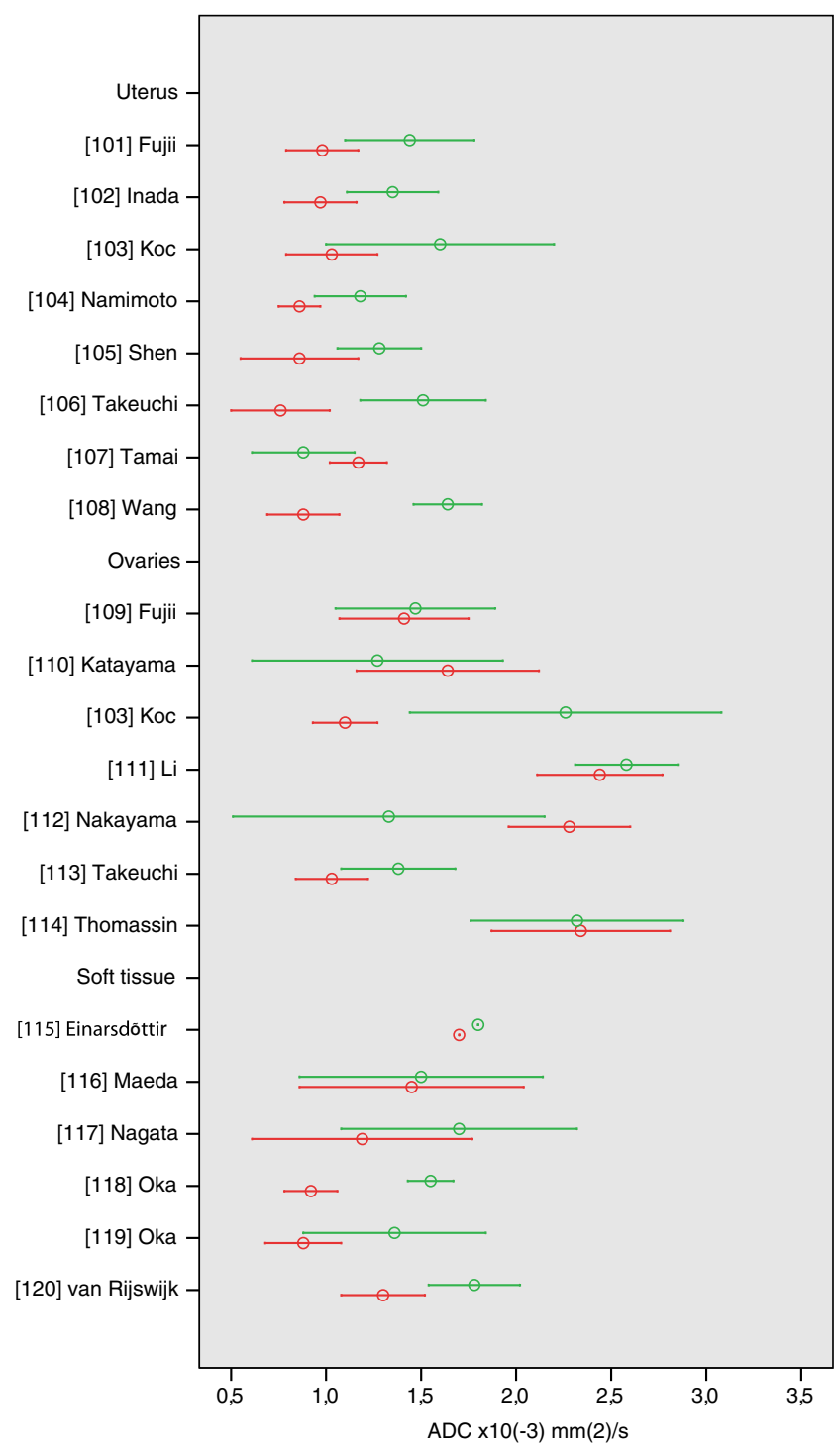

Fig. 8 Apparent diffusion coefficient (ADC) values of uterus, ovary, and soft tissue lesions. Reported mean (circles) $\mathrm{ADC} \pm \mathrm{SD}$ (whiskers) of malignant (red) vs. benign (green) tumours

$10^{-3} \mathrm{~mm}^{2} / \mathrm{s}$ (Fig. 8). Only one study [112] found a significant difference between mean ADC values of cystic components of benign $\left(1.33 \pm 0.82 \times 10^{-3} \mathrm{~mm}^{2} / \mathrm{s}\right)$ and malignant tumours $\left(2.28 \pm 0.32 \times 10^{-3} \mathrm{~mm}^{2} / \mathrm{s}\right)$. The ADC values of solid components of benign ovarian lesions (range $1.15 \pm$ 0.55 to $1.47 \pm 0.42 \times 10^{-3} \mathrm{~mm}^{2} / \mathrm{s}$ ) and malignant ovarian lesions (range $1.14 \pm 0.28$ to $1.41 \pm 0.34 \times 10^{-3} \mathrm{~mm}^{2} / \mathrm{s}$ ) were not significantly different $[109,114]$.

\section{Soft-tissue}

Six articles have been published in which the application of diffusion-weighted imaging and ADC measurement to the characterisation of soft-tissue tumours is discussed (ESM Table S14) [115-120]. Quality scores of these articles ranged from 33 to 
$67 \%$. One article focused on the differentiation between chronic expanding hematomas $(\mathrm{CEH})$ and malignant soft-tissue tumours and observed significantly $(P<0.01)$ higher mean ADC values in CEH $\left(1.55 \pm 0.121 \times 10^{-3} \mathrm{~mm}^{2} / \mathrm{s}\right)$ than in malignant tumours $\left(0.92 \pm 0.139 \times 10^{-3} \mathrm{~mm}^{2} / \mathrm{s}\right)$ [118]. Five authors studied ADC values in various benign and malignant tumours [115-117, 119, 120]. Mean ADC values of benign soft-tissue tumours (range of mean ADC values $1.36 \pm$ 0.48 to $1.80 \times 10^{-3} \mathrm{~mm}^{2} / \mathrm{s}$ ) overlapped with those of malignant soft-tissue tumours (range of mean $\mathrm{ADC}$ values $0.88 \pm 0.20$ to $1.70 \times 10^{-3} \mathrm{~mm}^{2} / \mathrm{s}$ ). Only one study found a significant difference between benign desmoid tumours and malignant softtissue tumours (Fig. 8) [118].

\section{Discussion}

Since its development in the early 1990s, the application of diffusion-weighted imaging has expanded from intracranial to extracranial disease and from detection of brain ischemia to assessment of tumour masses. Its potential additional value in oncological imaging lies in the fact that it provides functional tissue information, which can be combined with anatomical MR images to improve the specificity of lesion characterisation. Besides the qualitative assessment of signal intensity in DWI, images can be assessed quantitatively by the measurement of ADC values. We performed a systematic review of the recent literature in order to obtain an insight into the value of DWI and ADC measurement in differentiating benign from malignant tumour masses.

\section{Additional value of ADC measurement in tumour characterisation}

In DWI, tissue contrast is obtained through differences in free water motion between various tissue types and between normal and pathological tissues. The functional information provided by DWI and ADC measurement may be of value in tumour characterisation, complementary to the anatomical information obtained with conventional MRI sequences. Because of its high contrast-to-noise ratio, lesions with restricted diffusion are usually easily recognised on diffusion-weighted images [10]. A drawback of DWI is the relatively low spatial resolution of the images, compared with conventional T1- or T2-weighted MR images. Small lesions (i.e., below spatial resolution) may not be visible on DWI and ADC maps [51], and partial volume averaging is more likely to occur. Several of the reviewed studies excluded small lesions for this reason. Similarly, lesions with a degree of diffusivity equal to the surrounding normal tissue may not be easily distinguished on DWI images and ADC maps. Thus, not all lesions are suitable for ADC measurement.

The lowest mean ADC value of extracerebral benign lesions $\left(0.86 \times 10^{-3} \mathrm{~mm}^{2} / \mathrm{s}\right)$ was reported for Warthin tumours of the parotid glands, while benign renal cysts showed the highest mean ADC value $\left(3.82 \times 10^{-3} \mathrm{~mm}^{2} / \mathrm{s}\right)$. The lowest and highest mean ADC values reported for malignant lesions were $0.30 \times 10^{-3} \mathrm{~mm}^{2} / \mathrm{s}$ in thyroid carcinomas and $2.70 \times 10^{-3} \mathrm{~mm}^{2} / \mathrm{s}$ in malignant pancreatic lesions, respectively. The observed wide variation in ADC values within benign and malignant tumours can be partly explained by the wide variety of histological subtypes of proliferative tumours. In most malignant tumours, diffusion is restricted due to increased cellular density and decreased extracellular matrix volume, which impede free motion of water molecules [10, $121,122]$. However, some malignant tumours show increased diffusion due to an increase in intratumoural water content, which is the case in intratumoural edema and in cystic tumour components. The degree of serous or mucinous content and intratumoural hemorrhage also influences the signal intensity and ADC value through their effect on restriction of free proton diffusion and magnetic susceptibility of the tumour tissue. Furthermore, loss of cell membrane integrity in necrotic tumours may result in increased diffusion [10, 121, 122]. This was also demonstrated in the studies that compared $\mathrm{ADC}$ values of cerebral necrotic/cystic tumours and cerebral abscesses, in which high mean ADC values of necrotic tumours (ranging from $2.58 \pm 0.60$ to $2.84 \pm 0.30 \times$ $10^{-3} \mathrm{~mm}^{2} / \mathrm{s}$ ) were reported [13-20]. In cerebral abscesses restricted diffusion was observed, with mean $\mathrm{ADC}$ values ranging from $0.42 \pm 0.15$ to $0.91 \pm 0.65 \times 10^{-3} \mathrm{~mm}^{2} / \mathrm{s}$ [13-20]. It is postulated that the restricted diffusion in abscesses is attributable to high viscosity of pus resulting from high protein and different types of viable or dead cells, along with necrotic tissue and bacteria [123]. Mean ADC values in other benign or malignant cystic lesions in the body were comparable to the high values in malignant cerebral cystic tumours (1.45 to $\left.2.96 \times 10^{-3} \mathrm{~mm}^{2} / \mathrm{s}\right)$ [13-20]. For example, the following ranges of mean ADC values were described in various cystic lesions: $2.35 \pm 0.08$ to $2.65 \pm 0.30 \times 10^{-3} \mathrm{~mm}^{2} / \mathrm{s}$ in benign cystic breast lesions $[43,56], 1.902$ to $3.63 \times 10^{-3} \mathrm{~mm}^{2} / \mathrm{s}$ in simple liver cysts $[66,68-71,75,76,78], 1.33 \pm 0.82$ to $2.32 \pm 0.56 \times$ $10^{-3} \mathrm{~mm}^{2} / \mathrm{s}$ in cystic components of benign ovarian tumours [114] and $2.34 \pm 0.47 \times 10^{-3} \mathrm{~mm}^{2} / \mathrm{s}$ in cystic components of malignant ovarian tumours [114].

We observed significant differences in reported ADC values between benign and malignant tumours in the following tissues: brain abscesses vs. cystic brain tumours, meningiomas, breast, liver, and uterus. However, many studies showed considerable overlap between ADC values of benign and malignant tumours. The presence of overlap complicates potential prospective usage of these quantitative measurements, which calls for the use of "artificial" cut-off values.

In some organs, such as the salivary glands, thyroid, lungs, pancreas, and soft tissue, the reported data on the value of ADC measurements showed contradictory results. 
ADC measurement in these organs is unlikely to contribute to the differentiation between benign and malignant lesions. In the pancreas, $\mathrm{ADC}$ measurements fail to differentiate cysts. Furthermore, it is generally accepted that we need both high $b$-value DWI and ADC mapping for the diagnosis of solid pancreatic lesions. Likewise, we have observed widely varying reported $\mathrm{ADC}$ values of benign and malignant ovarian lesions. In cystic ovarian lesions, conventional MR imaging is often not conclusive and differentiation by ADC measurement would be useful. However, the reviewed studies that compare ADC values in cystic components of benign and malignant ovarian tumours showed contradictory results. Moreover, ADC values of solid components of benign and malignant cystic ovarian lesions were not significantly different [103, 109-114]. In several breast and liver studies, simple benign cysts were enrolled, which are well recognised on conventional (T1- and T2-weighted) imaging and usually do not cause diagnostic dilemmas. Including these cysts may overestimate the ability of ADC measurements to discriminate benign from malignant lesions. Another limitation of many studies included in this review was that benign lesions in particular were frequently confirmed by other imaging modalities and follow-up, without histological assessment. This is a common procedure in daily practice but may cause bias in the comparison of ADC values of benign and malignant tumours.

\section{Technical aspects of DWI and ADC measurement}

Quality of diffusion-weighted images and ADC measurements may vary when different MR imaging parameters and MR systems are used. The most important limitations of DWI are the low SNR and susceptibility to artefacts [10]. Strategies to optimise image quality often incorporate the use of parallel imaging techniques, fat-suppression techniques, and signal averaging. Additional factors that can influence measured ADC values are use of breath-hold, respiratory triggering, or free-breathing acquisition and direction of diffusion gradients. Diffusion-weighting gradients are commonly applied in three orthogonal directions, which is desirable particularly in tissues with anisotropic orientation such as brain and kidney, in which ADC values may differ among the $\mathrm{x}, \mathrm{y}$, and $\mathrm{z}$ directions [10].

Another important factor in DWI is the maximum $b$ value. When low $b$-values are applied, the ADC values tend to be higher due to the contribution of perfusion. This was shown by several studies that applied low $b$-values to ADC measurement of breast lesions $[42,52,56]$. On the other hand, among the reviewed studies on ADC values of liver lesions, the ADC values did not clearly differ between high and low $b$-values. In malignant tumours, a higher percentage of microvessels is present than in benign tissue [124]. Accordingly, perfusion may artificially increase the ADC in malignant lesions and complicate differentiation. Therefore, if ADC measurement is performed to differentiate tissues by their water diffusion characteristics exclusively, applying high maximum $b$-values may be preferable. However, signal-to-noise ratios decrease as the $b$-value increases, thus limiting the maximum $b$-value. Another way of minimising contribution of perfusion to the ADC value is to select minimum $b$-values higher than $0 \mathrm{~s} / \mathrm{mm}^{2}$ (e.g., $100 \mathrm{~s} / \mathrm{mm}^{2}$ ), which was done in several reviewed studies [19, 41, 69]. Optimal $b$-values should be chosen for each organ, however, no consensus or guidelines are available for that purpose. In the reviewed articles, various methods of ADC measurement have been used. ADC measurement is performed by

Table 3 Checklist for reporting diffusion-weighted imaging (DWI) technique in studies on apparent diffusion coefficient (ADC) measurement in tumour characterisation (recommended minimum requirements)

DWI parameters

Field strength $(\mathrm{T})$

Coil type (i.e., built-in body coil/surface coils)

Pulse sequence [e.g., single-shot spin-echo/single-shot double spinecho/multi-shot spin-echo, echo planar imaging (EPI)/non-EPI, etc.]

Repetition time, echo time (ms)

$b$-values $\left(\mathrm{s} / \mathrm{mm}^{2}\right)$

Directions of diffusion-weighting gradients

Fat saturation technique (e.g., fat saturation, inversion recovery, water selection only, etc.)

Number of excitations

Parallel acquisition factor

Echo train length

Respiratory motion correction technique (i.e., breath-hold/respiratory gating/none)

Cardiac motion correction technique (i.e., ECG triggering/finger pulse triggering/none)

Voxel size $\left(\mathrm{mm}^{3}\right)$

Receiver bandwidth

Acquisition of DWI data before or after intravenous contrast administration

Method of ADC calculation

Applied model for ADC calculation (e.g., monoexponential, biexponential, etc.)

$b$-values that were used to calculate the ADC

Method of ADC measurement

Description of which portion of the tumour was measured (e.g., whole tumour, only enhancing and/or solid portions, etc.)

Description of ROI margins (i.e., distance from tumour periphery)

ROI shape and size (fixed or variable)

Single or multiple slice ROI measurement

Verification of ROI position on diffusion-weighted images that were used to calculate the ADC map

$T$ Tesla, EPI echo planar imaging, ECG electrocardiogram, $R O I$ region of interest 
placing regions of interest (ROI) in the lesion on the acquired ADC maps. Variations occurred in applied size and shape of the ROI, use of T1/T2 MR images for guidance of ROI placement on ADC map, and averaging of multiple ROIs. As the ROI placement is usually performed manually, training is required to optimise the reproducibility (minimise interobserver variation) of ADC measurement. Furthermore, in case of lesions with both solid and cystic components, a consensus on localisation of ROI (in solid or cystic part of lesion) should be established.

\section{Study limitations}

Selection of eligible articles and assessment of study quality was performed by one author only, which could be considered a limitation. However, in a study by Whiting et al., reproducibility of the QUADAS instrument has been reported to be good [125]. Three reviewers independently rated the quality of 30 studies using QUADAS. The proportion of agreements between each reviewer and the final consensus rating was assessed. This was done for all QUADAS items combined and for each individual item. Over all items, the agreements between each of the reviewers and the final consensus rating were 91, 90, and $85 \%$. The results for individual QUADAS items ranged from 50 to $100 \%$ with a median value of $90 \%$ [125].

As this study aimed to evaluate the potential of ADC measurements to differentiate between benign and malignant lesions in the body, we included a large number of studies on ADC measurement in a variety of organs. Consequently, heterogeneity in study methods and applied MRI parameters was observed, which precluded the performance of statistical meta-analysis.

Towards standardisation of ADC measurement and reporting

If $\mathrm{ADC}$ measurements are to be routinely used in clinical practice, standardisation of protocols across institutions is required in order to improve reproducibility. Differences in MR protocols and in histological types of lesions enrolled in the studies contribute to the variation in reported ADC values. In order to obtain reliable data on the value of ADC measurement in clinical practice, two issues need to be addressed. Firstly, applied MR parameters differ among hospitals, which complicates a direct comparison of ADC values. Therefore, standardised diffusion-weighted MRI protocols need to be established to ensure reproducibility at different centers [126, 127]. In particular, the use of $b$-values and method of ADC measurement should be standardised for clinical application, adjusted to each organ of interest. Secondly, due to incomplete reporting of study methods, comparison of ADC values among studies becomes challenging. Detailed reporting of patient population and data collection is important to assess generalisability of study results. Notably, standardised acquisition and reporting may not fully solve this problem, as differences in SNR and image quality across various MR systems may still cause some variation in measured ADC values. Padhani et al. have provided useful recommendations for the use of DWI as a cancer biomarker, both for the choice of methods of measurement and analysis and for the reporting of data [127]. Furthermore, the Standards for Reporting of Diagnostic Accuracy (STARD) criteria provide a good guideline for the reporting of study methods in diagnostic accuracy studies [128]. When key DWI parameters are well reported, differences in reported ADC values may be easier to evaluate. In addition, we suggest a short checklist of DWI parameters that can serve as a guideline for reporting in studies on ADC measurement for tumour characterisation (Table 3).

\section{Conclusion}

Reported ADC values among studies and between benign and malignant lesions differ considerably. In several tumours, such as brain abscesses vs. cystic brain tumours, meningiomas, and breast, liver, and uterine tumours, ADC measurement may be of value to discriminate benignancy from malignancy. However, in other organs, such as the salivary glands, thyroid, lungs, pancreas, and soft tissue, the ADC value does not appear to contribute to tumour characterisation.

One of the challenges that must be faced to enable widespread adoption of ADC measurement in clinical practice is standardisation of study methods and reporting. The development of organ-specific guidelines for DWI acquisition and ADC measurement and checklists for reporting of results may facilitate comparison of study results and contribute to the implementation of ADC measurement for tumour characterisation in the clinical setting.

Acknowledgments This work was supported by the ZonMW Programme for Health Care Efficiency Research (grant number 8082310-98-08012). The authors have no other relevant affiliations or financial involvement with any organization or entity with a financial interest in or financial conflict with the subject matter or materials discussed in the manuscript apart from those disclosed.

Open Access This article is distributed under the terms of the Creative Commons Attribution License which permits any use, distribution, and reproduction in any medium, provided the original author(s) and the source are credited.

\section{References}

1. Bazot M, Daraï E, Nasser-Slaba J, Lafont C, Thomassin-Naggara I (2008) Value of magnetic resonance imaging for the diagnosis of ovarian tumors: a review. J Comput Assist Tomogr 32:712-723 
2. Schima W (2006) MRI of the pancreas: tumours and tumoursimulating processes. Cancer Imaging 6:199-203

3. Saar B, Kellner-Weldon F (2008) Radiological diagnosis of hepatocellular carcinoma. Liver Int 28(2):189-199

4. Kuhl CK (2008) Concepts for differential diagnosis in breast MR imaging. Magn Reson Imaging Clin N Am 14(3):305-328

5. Le Bihan D, Breton E, Lallemand D, Aubin ML, Vignaud J, LavalJeantet M (1988) Separation of diffusion and perfusion in intravoxel incoherent motion MR imaging. Radiology 168(2):497-505

6. Schaefer PW, Grant PE, Gonzalez RG (2000) Diffusion-weighed MR imaging of the brain. Radiology 217(3):331-345

7. Le Bihan D, Breton E, Lallemand D, Grenier P, Cabanis E, LavalJeantet M (1986) MR imaging of intravoxel incoherent motions: application to diffusion and perfusion in neurologic disorders. Radiology 161(2):401-407

8. Guo AC, Cummings TJ, Dash RC, Provenzale JM (2002) Lymphomas and high-grade astrocytomas: comparison of water diffusibility and histologic characteristics. Radiology 224(1):177-183

9. Sugahara T, Korogi Y, Kochi M, Ikushima I, Shigematu Y, Hirai T, Okuda T, Liang L, Ge Y, Komohara Y, Ushio Y, Takahashi M (1999) Usefulness of diffusion-weighted MRI with eco-planar technique in the evaluation of cellularity in gliomas. J Magn Reson Imaging 9(1):53-60

10. Koh DW, Collins DJ (2007) Diffusion-weighted MRI in the body: applications and challenges in oncology. AJR Am J Roentgenol 188(2):1622-1635

11. Kwee TC, Takahara T, Ochiai R, Nievelstein RAJ, Luiten PR (2008) Diffusion-weighted whole-body imaging with background body signal suppression (DWIBS): features and potential applications in oncology. Eur Radiol 18(9):1937-1952

12. Whiting P, Rutjes AWS, Reitsma JB, Bossuyt PMM, Kleijnen J (2003) The development of QUADAS: a tool for the quality assessment of diagnostic accuracy included in systematic reviews. BMC Med Res Methodol 3:25

13. Chan JHM, Tsui EYK, Chau LF, Chow KY, Chan MSM, Yuen MK, Chan TL, Cheng WK, Wong KPC (2002) Discrimination of an infected brain tumor from a cerebral abscess by combined MR perfusion and diffusion imaging. Comput Med Imaging Graph 26:19-23

14. Chang SC, Lai PH, Chen WL, Weng HH, Ho JT, Wang JS, Chang CY, Pan HB, Yang CF (2002) Diffusion-weighted MRI features of brain abscess and cystic or necrotic brain tumors. Comparison with conventional MRI. Clin Imaging 26(4):227-236

15. Chiang IC, Hsieh TJ, Chiu ML, Liu GC, Kuo YT, Lin WC (2009) Distinction between pyogenic brain abscess and necrotic brain tumor using 3-tesla MR spectroscopy, diffusion and perfusion imaging. Br J Radiol 82(982):813-820

16. Guzman R, Barth A, Lövblad KO, El-Koussy M, Weis J, Schroth G, Seiler RW (2002) Use of diffusion-weighted magnetic resonance imaging in differentiating purulent brain processes from cystic brain tumors. J Neurosurg 97:1101-1107

17. Mishra AM, Gupta RK, Jaggi RS, Reddy JS, Jha DK, Husain N, Prasad KN, Behari S, Husain M (2004) Role of diffusionweighted imaging and in vivo proton magnetic resonance spectroscopy in the differential diagnosis of ring-enhancing intracranial cystic mass lesions. J Comput Assist Tomogr 28(4):540-547

18. Mucchio CF, Esposito G, Bartolini A, Cerase A (2008) Cerebral abscesses and necrotic cerebral tumours: differential diagnosis by perfusion-weighted magnetic resonance imaging. Radiol Med 113:747-757

19. Noguchi K, Watanabe N, Nagayoshi T, Kanazawa T, Toyoshima S, Shimizu M, Seto H (1999) Role of diffusion weighted echoplanar MRI in distinguishing between brain abscess and tumour: a preliminary report. Neuroradiology 41(3):171-174

20. Park SH, Chang KH, Song IC, Kim YJ, Kim SH, Han MH (2000) Diffusion-weighted MRI in cystic or necrotic intracranial lesions. Neuroradiology 42:716-721
21. Hakyemez B, Yildirim N, Gokalp G, Erdogan C, Parlak M (2006) The contribution of diffusion-weighted MR imaging to distinguishing typical from atypical meningiomas. Neuroradiology 48(8):513-520

22. Nagar VA, Ye JR, Ng WH, Chan YH, Hui F, Lee CK, Lim CC (2008) Diffusion-weighted MR imaging: diagnosing atypical or malignant meningiomas and detecting tumor dedifferentiation. Am J Neuroradiol 29(6):1147-1152

23. Pavlisa G, Rados M, Pazanin L, Padovan RS, Ozretic D, Pavlisa G (2008) Characteristics of typical and atypical meningiomas on ADC maps with respect to schwannomas. Clin Imaging 32(1):22-27

24. Santelli L, Gaetano R, Della Puppa A, Ermani M, Scienza R, d'Avella D, Manara R (2010) Diffusion-weighted imaging does not predict histological grading in meningiomas. Acta Neurochir 152:1315-1319

25. Sanverdi SE, Ozgen B, Oguz KK, Mut M, Dolgun A, Soylemezoglu F, Cila A (2011) Is diffusion-weighted imaging useful in grading and differentiating histopathological subtypes of meningiomas? Eur J Radiol. doi:10.1016/j.ejrad.2011.06.031

26. Toh CH, Castillo M, Wong AM, Wei KC, Wong HF, Ng SH, Wan YL (2008) Differentiation between classic and atypical meningiomas with use of diffusion tensor imaging. Am J Neuroradiol 29 (9):1630-1635

27. Habermann CR, Arndt C, Graessner J, Diestel L, Petersen KU, Reitmeier F, Ussmueller JO, Adam G, Jaehne M (2009) Diffusion-weighted echo-planar MR imaging of primary parotid gland tumors: is a prediction of different histologic subtypes possible? Am J Neuroradiol 30(3):591-596

28. Ikeda M, Motoori K, Hanazawa T, Nagai Y, Yamamoto S, Ueda T, Funatsu H, Ito H (2004) Warthin tumor of the parotid gland: diagnostic value of MR imaging with histopathologic correlation. Am J Neuroradiol 25(7):1256-1262

29. Matsushima N, Maeda M, Takamura M, Takeda K (2007) Apparent diffusion coefficients of benign and malignant salivary gland tumors. Comparison to histopathological findings. J Neuroradiol 34:183-189

30. Motoori K, Yamamoto S, Ueda T, Nakano K, Muto T, Nagai Y, Ikeda M, Funatsu H, Ito H (2004) Inter- and intratumoral variability in magnetic resonance imaging of pleomorphic adenoma. $\mathrm{J}$ Comput Assist Tomogr 28(2):233-246

31. Yabuuchi H, Matsuo Y, Kamitani T, Setoguchi T, Okafuji T, Soeda H, Sakai S, Hatakenaka M, Nakashima T, Oda Y, Honda H (2008) Parotid gland tumors: can addition of diffusionweighted MR imaging to dynamic contrast-enhanced MR imaging improve diagnostic accuracy in characterization? Radiology 249(3):909-916

32. Yerli H, Aydin E, Haberal N, Harman A, Kaskati T, Alibek S (2010) Diagnosing common parotid tumours with magnetic resonance imaging including diffusion-weigthed imaging vs. fine-needle aspiration cytology: a comparative study. Denomaxillofac Radiol 39:349-255

33. Abdel Razek AAK, Sadek AG, Kombar OR, Elmahdy TE, Nada N (2008) Role of apparent diffusion coefficient values in differentiation between malignant and benign solitary thyroid nodules. Am J Neuroradiol 29(3):563-568

34. Bozgeyik Z, Coskun S, Dagle F, Ozkan Y, Sahpaz F, Ogur E (2009) Diffusion-weighted MR imaging of thyroid nodules. Neuroradiology 51(3):193-198

35. Erdem G, Erdem T, Karakas HM, Mutlu DY, Firat AK, Sahin I, Alkan A (2010) Diffusion-weighted images differentiate benign from malignant thyroid nodules. J Magn Reson Imaging 31:94-100

36. Mutlu H, Sivrioglu AK, Sonmez G, Velioglu M, Sildiroglu HO, Basekim CC, Kizilkaya E (2012) Role of apparent diffusion coefficient values and diffusion-weigthed magnetic resonance imaging in differentiation between benign and malignant thyroid nodules. Clin Imaging 36:1-7 
37. Nakahira M, Saito N, Murata S, Sugasawa M, Shimamura Y, Morita K, Takajyo F, Omura G, Matsumura S (2011) Quantitative diffusion-weighted magnetic resonance imaging as a powerful adjunct to fine needle aspiration cytology for assessment of cold thyroid nodules. Am J Otolaryngol. doi:10.1016/j.amjoto.2011.10.013

38. Schueller-Weidekamm C, Schueller G, Kaserer K, Scheuba C, Ringl H, Weber M, Czerny C, Heneth AM (2010) Diagnostic value of sonography, ultrasound-guided fine-needle aspiration cytology, and diffusion-weighted MRI in the characterization of cold thyroid nodules. Eur J Radiol 73:538-544

39. Baltzer PAT, Renz DM, Herrmann KH, Dietzel M, Krumbein I, Gajda M, Camara O, Reichenbach JR, Kaiser WA (2009) Diffusion-weighted imaging (DWI) in MR mammography (MRM): clinical comparison of echo planar imaging (EPI) and half-Fourier single-shot turbo spin echo (HASTE) diffusion techniques. Eur Radiol 19(7):1612-1620

40. Belli P, Constantini M, Bufi E, Magistrelli A, La Torre G, Bonomo L (2010) Diffusion-weighted imaging in breast lesion evaluation. Radiol Med 115(1):51-69

41. Bogner W, Gruber S, Pinker K, Grabner G, Stadlbauer A, Weber M, Moser E, Heilbich TH, Trattnig S (2009) Diffusion-weighted MR for differentiation of breast lesions at 3.0 T: how does selection of diffusion protocols affect diagnosis? Radiology 253(2):341-351

42. Corum CA, McIntosh AD, Bolan PJ, Nelson M, Snyder AL, Powell NJ, Boyum J, Emory TH, Yee D, Tuttle TM, Everson LI, Garwood M (2009) Feasibility of single-voxel MRS measurement of apparent diffusion coefficient of water in breast tumors. Magn Reson Med 61(5):1232-1237

43. Guo Y, Cai YQ, Cai ZL, Gao YG, An NY, Ma L, Mahankali S, Gao JH (2002) Differentiation of clinically benign and malignant breast lesions using diffusion-weighting imaging. J Magn Res Imaging 16(2):172-178

44. Hatakenaka M, Soeda H, Yabuuchi H, Matsuo Y, Kamitani T, Oda Y, Tsuneyoshi M, Honda H (2008) Apparent diffusion coefficients of breast tumors: clinical application. Magn Reson Med Sci 7(1):23-29

45. Hirano M, Satake H, Ishigaki S, Ikeda M, Kawai H, Naganawa S (2012) Diffusion-weighted imaging of breast masses: comparison of diagnostic performance using various apparent diffusion coefficient parameters. AJR Am J Roentgenol 198:717-722

46. Jin G, An N, Jacobs MA, Li K (2010) The role of parallel diffusion-weighted imaging and apparent diffusion coefficient (ADC) map values for evaluating breast lesions: preliminary results. Acad Radiol 17(4):456-463

47. Kinoshita T, Yashiro N, Ihara N, Funatu H, Fukama E, Narita M (2002) Diffusion-weighted half-Fourier single-shot turbo spin echo imaging in breast tumors: differentiation of invasive ductal carcinoma from fibroadenoma. J Comput Assist Tomogr 26(6):1042-1046

48. Kul S, Cansu A, Alhan E, Dinc H, Gunes G, Reis A (2011) Contribution of diffusion weighted imaging to dynamic contrastenhanced MRI of the characterization of breast tumors. AJR Am J Roentgenol 196:210-217

49. Kuroki Y, Nasu K, Kuroki S, Murakami K, Hayashi T, Sekiguchi R, Nawano S (2004) Diffusion-weighted imaging of breast cancer with the sensitivity encoding technique: analysis of the apparent diffusion coefficient value. Magn Reson Med Sci 3(2):79-85

50. Lo GG, Ai V, Chan JKF, Li KW, Cheung PSY, Wong TT, Ma M, Lee R, Chien D (2009) Diffusion-weighted magnetic resonance imaging of breast lesions: first experiences at $3 \mathrm{~T}$. J Comput Assist Tomogr 33(1):63-69

51. Park MJ, Cha ES, Kang BJ, Ihn YK, Baik JH (2007) The role of diffusion-weighted imaging and the apparent diffusion coefficient (ADC) values for breast tumors. Korean J Radiol 8 (5):390-396
52. Partridge SC, DeMartini WB, Kurland BF, Eby PR, White SW, Lehman CD (2010) Differential diagnosis of mammographically and clinically occult breast lesions on diffusion-weighted MRI. J Magn Res Imaging 31:562-570

53. Pereira FP, Martins G, Figueiredo E, Domingues MN, Domingues RC, da Fonseca LM, Gasparetto EL (2009) Assessment of breast lesions with diffusion-weighted MRI: comparing the use of different $b$ values. AJR Am J Roentgenol 193 (4):1030-1035

54. Rubesova E, Grell AS, De Maertelaer V, Metens T, Chao SL, Lemort M (2006) Quantitative diffusion imaging in breast cancer: a clinical prospective study. J Magn Reson Imaging 24:319-324

55. Satake H, Nishio A, Ikeda M, Ishigaki S, Shimamoto K, Hirano M, Naganawa S (2011) Predictive value for malignancy of suspicious breast masses of BI-RADS categories 4 and 5 using ultrasound elastography and MR diffusion-weighted imaging. AJR Am J Roentgenol 196:202-209

56. Sinha S, Lucas-Quesada FA, Sinha U, DeBruhl N, Bassett LW (2002) In vivo diffusion-weighted MRI of the breast: potential for lesion characterization. J Magn Reson Imaging 15(6):693-704

57. Sonmez G, Cuce F, Mutlu H, Incedayi M, Ozturk E, Sildiroglu O, Velioglu M, Bashekim CC, Kizilkaya E (2011) Value of diffusion-weighted MRI in the differentiation of benign and malign breast lesions. Wien Klin Wochenschr 123:655-661

58. Stadlbauer A, Bernt R, Gruber S, Bogner W, Pinker K, van der Riet W, Haller J, Salomonowitz E (2009) Diffusion-weighted MR imaging with background body signal suppression (DWIBS) for the diagnosis of malignant and benign breast lesions. Eur Radiol 19(10):2349-2356

59. Tozaki M, Fukuma E (2009) ${ }^{\mathrm{I}} \mathrm{H}$ MR spectroscopy and diffusionweighted imaging of the breast: are they useful tools for characterizing breast lesions before biopsy? AJR Am J Roentgenol 193:840-849

60. Woodhams R, Matsunaga K, Kan S, Hata H, Ozaki M, Iwabuchi K, Kuranami M, Watanabe M, Hayakawa K (2005) ADC mapping of benign and malignant breast tumors. Magn Reson Med Sci 4(1):35-42

61. Woodhams R, Kakita S, Hata H, Iwabuchi K, Umeoka S, Mountford C, Hatabu H (2009) Diffusion-weighted imaging of mucinous carcinoma of the breast: evaluation of apparent diffusion coefficient and signal intensity in correlation with histologic findings. AJR Am J Roentgenol 193(1):260-266

62. Yili Z, Xiaoyan H, Hongwen D, Yun Z, Xin C, Peng W, Youmin G (2009) The value of diffusion-weighted imaging in assessing the ADC changes of tissues adjacent to breast carcinoma. BMC Cancer 9:18

63. Uto T, Takehara Y, Nakamura Y, Naito T, Hashimoto D, Inui N, Suda T, Nakamura H, Chida K (2009) Higher sensitivity and specificity for diffusion-weighted imaging of malignant lung lesions without apparent diffusion coefficient quantification. Radiology 252(1):247-254

64. Liu H, Liu Y, Yu T, Ye N (2010) Usefulness of diffusionweighted MR imaging in the evaluation of pulmonary lesions. Eur Radiol 20(4):807-815

65. Battal B, Kocaoglu M, Akgun V, Karademir I, Deveci S, Guvenc I, Bulakbasi N (2011) Diffusion-weighted imaging in the characterization of focal liver lesions: efficacy of visual assessment. J Comput Assist Tomogr 35:326-331

66. Choi JS, Kim MJ, Choi JY, Park MS, Lim JS, Kim KW (2010) Diffusion-weighted MR imaging of liver on 3.0-Tesla system: effect of intravenous administration of gadoxetic acid disodium. Eur Radiol 20(5):1052-1060

67. Coenegrachts K, Delanote J, ter Beek L, Haspeslagh M, Bipat S, Stoker J, Steyaert L, Rigauts H (2009) Evaluation of true diffusion, 
perfusion factor, and apparent diffusion coefficient in non-necrotic liver metastases and uncomplicated liver haemangiomas using black-blood echo planar imaging. Eur J Radiol 69(1):131-138

68. Demir OI, Obuz F, Sagol O, Dicle O (2007) Contribution of diffusion-weighted MRI to the differential diagnosis of hepatic masses. Diagn Interv Radiol 13(2):81-86

69. Holzapfel K, Bruegel M, Eiber M, Ganter C, Schuster T, Heinrich P, Rummeny EJ, Gaa J (2010) Characterization of small ( $\leq 10 \mathrm{~mm})$ focal liver lesions: value of respiratory-triggered echo-planar diffusion-weighted MR imaging. Eur J Radiol 76(1):89-95

70. Kim T, Murakami T, Takahashi S, Hori M, Tsuda K, Nakamura H (1999) Diffusion-weighted single-shot echoplanar MR imaging for liver disease. AJR Am J Roentgenol 173(2):393-398

71. Koike N, Cho A, Nasu K, Seto K, Nagaya S, Ohshima Y, Ohkohchi N (2009) Role of diffusion-weighted magnetic resonance imaging in the differential diagnosis of focal hepatic lesions. World J Gastroenterol 15(46):5805-5812

72. Miller FH, Hammond N, Siddiqi A, Shroff S, Khatri G, Wang Y, Mennick LB, Nikolaidis P (2010) Utility of diffusion-weighted MRI in distinguishing benign and malignant hepatic lesions. $J$ Magn Res Imaging 32:138-147

73. Onur MR, Cicekci M, Kayali A, Poyraz AK, Kocakoc (2012) The role of ADC measurement in differential diagnosis of focal hepatic lesions. EJR 81:e171-e176

74. Papanikolaou N, Gourtsoyianni S, Yarmenitis S, Maris T, Gourtsoyiannis N (2010) Comparison between two-point and four-point methods for quantification of apparent diffusion coefficient of normal liver parenchyma and focal lesions. Value of normalization with spleen. EJR 73(2):305-309

75. Parikh T, Drew SJ, Lee VS, Wong S, Hecht EM, Babb JS, Taouli B (2008) Focal liver lesion detection and characterization with diffusion-weighted MR imaging: comparison with standard breath-hold T2-weighted imaging. Radiology 246(3):812-822

76. Sandrasegaran K, Akisik FM, Lin C, Tahir B, Rajan J, Aisen AM (2009) The value of diffusion-weighted imaging in characterizing focal liver masses. Acad Radiol 16:1208-1214

77. Taouli B, Sandberg A, Stemmer A, Parikh T, Wong S, Xu J, Lee VS (2009) Diffusion-weighted imaging of the liver: comparison of navigator triggered and breathhold acquisitions. J Magn Reson Imaging 30:561-568

78. Taouli B, Vilgrain V, Dumont E, Daire JL, Fan B, Menu Y (2003) Evaluation of liver diffusion isotropy and characterization of focal hepatic lesions with two single-shot echo-planar MR imaging sequences: prospective study in 66 patients. Radiology 226 (1):71-78

79. Sugita R, Yamazaki T, Furuta A, Itoh K, Fujita N, Takahashi S (2009) High b-value diffusion-weighted MRI for detecting gallbladder carcinoma: preliminary study and results. Eur Radiol 19 (7):1794-1798

80. Fattahi R, Balci C, Perman WH, Hsueh EC, Alkaade S, Havlioglu N, Burton FR (2009) Pancreatic diffusion-weighted imaging (DWI): comparison between mass-forming focal pancreatitis (FP), pancreatic cancer (PC), and normal pancreas. J Magn Res Imaging 29(2):350-356

81. Huang WC, Sheng J, Chen SY, Lu JP (2011) Differentiation between pancreatic carcinoma and mass-forming chronic pancreatitis: usefulness of high $b$ value diffusion-weighted imaging. $J$ Dig Dis 12:401-408

82. Kamisawa T, Takuma K, Anjiki H, Egawa N, Hata T, Kurata M, Honda G, Tsurata K, Suzuki M, Kamata N, Sasaki T (2010) Differentiation of autoimmune pancreatitis from pancreatic cancer by diffusion-weighted MRI. Am J Gastroenterol 105:18701875

83. Kartalis N, Lindholm TL, Aspelin P, Permert J, Albiin N (2009) Diffusion-weighted magnetic resonance imaging of pancreas tumours. Eur Radiol 19(8):1981-1990
84. Klauss M, Lemke A, Grünberg K, Simon D, Re TJ, Wente MN, Laun FB, Kauczor HU, Delorme S, Grenacher L, Stieltjes B (2011) Intravoxel incoherent motion MRI for the differentiation between mass forming chronic pancreatitis and pancreatic carcinoma. Invest Radiol 46:57-63

85. Lee SS, Byun JH, Park BJ, Park SH, Kim N, Park B, Kim JK, Lee MG (2008) Quantitative analysis of diffusion-weighted magnetic resonance imaging of the pancreas: usefulness in characterizing solid pancreatic masses. J Magn Res Imaging 28(4):928-936

86. Sandrasegaran K, Akisik FM, Patel AA, Rydberd M, Cramer HM, Agaram NP, Schmidt CM (2011) Diffusion-weighted imaging in characterization of cystic pancreatic lesions. Clin Radiol 66:808-814

87. Takeuchi M, Matsuzaki K, Kubo H, Nishitani H (2008) High-bvalue diffusion-weighted magnetic resonance imaging of pancreatic cancer and mass-forming chronic pancreatitis: preliminary results. Acta Radiol 49(4):383-386

88. Yamashita Y, Naminoto T, Mitsuzaki K, Urata J, Tsuchigame T, Takahashi M, Ogawa M (1998) Mucin-producing tumor of the pancreas: diagnostic value of diffusion-weighted echo-planar MR imaging. Radiology 208(3):605-609

89. Abdel Razek AAK, Farouk A, Mousa A, Nabil N (2011) Role of diffusion-weighted magnetic resonance imaging in characterization of renal tumors. J Comput Assist Tomogr 35:332-336

90. Doganay S, Kocakoc E, Cicekci M, Aglamis S, Akpolat N, Orhan I (2011) Ability and utility of diffusion-weighted MRI with different $b$ values in the evaluation of benign and malignant renal lesions. Clin Radiol 66:420-425

91. Kilickesmez O, Inci E, Atilla S, Tasdelen N, Yetimoglu B, Yencilek F, Gurmen N (2009) Diffusion-weighted imaging of the renal and adrenal lesions. J Comput Assist Tomogr 33:828-833

92. Kim S, Jain M, Harris AB, Lee VS, Babb JS, Sigmund EE, Rueff LE, Taouli B (2009) T1 hyperintense renal lesions: characterization with diffusion-weighted MR imaging versus contrast-enhanced MR imaging. Radiology 251(3):796-807

93. Sandrasegaran K, Sundaram CP, Ramaswamy R, Akisik FM, Rydberg MP, Lin C, Aisen AM (2010) Usefulness of diffusionweighted imaging in the evaluation of renal masses. AJR Am J Roentgenol 194:438-445

94. Taouli B, Thakur RK, Mannelli L, Babb JS, Kim S, Hecht EM, Lee VS, Israel GM (2009) Renal lesions: characterization with diffusion-weighted imaging versus contrast-enhanced MR imaging. Radiology 251(2):298-407

95. Yoshikawa T, Kawamitsu H, Mitchell DG, Ohno Y, Ku Y, Seo Y, Fujii M, Sugimura K (2006) ADC measurement of abdominal organs and lesions using parallel imaging technique. AJR Am J Roentgenol 187:1521-1530

96. Zhang J, Tehrani YM, Wang L, Ishill NM, Schwartz LH, Hricak H (2008) Renal masses: characterization with diffusion-weighted MR imaging — a preliminary experience. Radiology 247(2):458 464

97. Miller FH, Wang Y, McCarthy RJ, Yaghmai V, Merrick L, Larson A, Berggruen S, Casalino DD, Nikolaidis P (2010) Utility of diffusion-weighted MRI in characterization of adrenal lesions. AJR Am J Roentgenol 194(2):W179-W185

98. Sandrasegaran K, Patel A, Ramaswamy R, Samuel VP, Northcutt BG, Frank MS, Francis IR (2011) Characterization of adrenal masses with diffusion-weighted imaging. AJR Am J Roentgenol 197:132-138

99. Song J, Zhang C, Liu Q, Yu T, Jiang X, Xia Q, Zhang Y, Blanco Sequeiros R (2011) Utility of chemical shift and diffusionweighted imaging in characterization of hyperattenuating adrenal lesions at 3.0 T. EJR. doi:10.1016/j.ejrad.2011.09.016

100. Tsushima Y, Takahashi-Taketomi A, Endo K (2009) Diagnostic utility of diffusion-weighted MR imaging and apparent diffusion coefficient value for the diagnosis of adrenal tumors. J Magn Reson Imaging 29(1):112-117 
101. Fujii S, Matsusue E, Kigawa J, Sato S, Kanasaki Y, Nakanishi J, Sugihara S, Kaminou T, Terakawa N, Ogawa T (2008) Diagnostic accuracy of the apparent diffusion coefficient in differentiating benign from malignant uterine endometrial cavity lesions: initial results. Eur Radiol 18(2):384-389

102. Inada $Y$, Matsuki M, Nakai G, Tatsugami F, Tanikake M, Narabayashi I, Yamada T, Tsuji M (2009) Body diffusionweighted MR imaging of uterine endometrial cancer: is it helpful in the detection of cancer in nonenhanced MR imaging? EJR 70 (1):122-127

103. Koc Z, Erbay G, Ulusan S, Seydaoglu G, Aka-Bolat F (2012) Optimization of $b$ value in diffusion-weighted MRI for characterization of Benign and malignant gynaecological lesions. J Magn Res Imaging 35:650-659

104. Namimoto T, Yamashita Y, Awai K, Nakaura T, Yanaga Y, Hirai T, Saito T, Katabuchi H (2009) Combined use of T2-weighted and diffusion-weighted 3-T MR imaging for differentiating uterine sarcomas from benign leiomyomas. Eur Radiol 19(11):2756-2764

105. Shen SH, Chiou YY, Wang JH, Yen MS, Lee RC, Lai CR, Chang CY (2008) Diffusion-weighted single-shot echoplanar imaging with parallel technique in assessment of endometrial cancer. AJR Am J Roentgenol 190:481-488

106. Takeuchi M, Matsuzaki K, Nishitani H (2009) Hyperintense uterine myometrial masses on T2-weighted magnetic resonance imaging: differentiation with diffusion-weighted magnetic resonance imaging. J Comput Assist Tomogr 33:834-837

107. Tamai KI, Koyama T, Saga T, Morisawa N, Fujimoto K, Mikami Y, Togashi K (2008) The utility of diffusion-weighted MR imaging for differentiating uterine sarcomas from benign leiomyomas. Eur Radiol 18:723-730

108. Wang J, Yu T, Bai R, Sun H, Zhao X, Li Y (2010) The value of the apparent diffusion coefficient in differentiating stage IA endometrial carcinoma from normal endometrium and benign diseases of the endometrium: initial study at 3-T magnetic resonance scanner. J Comput Assist Tomogr 34:332-337

109. Fujii S, Kakite S, Nishihara K, Kanasaki Y, Harada T, Kigawa J, Kaminou T, Ogawa T (2008) Diagnostic accuracy of diffusionweighted imaging in differentiating benign from malignant ovarian lesions. J Magn Reson Imaging 28:1149-1156

110. Katayama M, Masui T, Kobayashi S, Ito T, Sakahara H, Nozaki A, Kabasawa H (2002) Diffusion-weighted echo planar imaging of ovarian tumors: is it useful to measure apparent diffusion coefficients? J Comput Assist Tomogr 26(2):250-256

111. Li W, Chu C, Cui Y, Zhang P, Zhu M (2011) Diffusion-weighted MRI: a useful technique to discriminate benign versus malignant ovarian surface epithelial tumors with solid and cystic components. Abdom Imaging. doi:10.1007/s00261-011-9814-x

112. Nakayama T, Yoshimitsu K, Irie H, Aibe H, Tajima T, Nishie A, Asayama Y, Matake K, Kakihara D, Matsuura S, Nakano H, Honda H (2005) Diffusion-weighted echo-planar MR imaging and ADC mapping in the differential diagnosis of ovarian cystic masses: usefulness of detecting keratinoid substances in mature cystic teratomas. J Magn Reson Imaging 22(2):271-278

113. Takeuchi M, Matsuzaki K, Nishitani H (2010) Diffusionweighted magnetic resonance imaging of ovarian tumors: differentiation of benign and malignant solid components of ovarian masses. J Comput Assist Tomogr 34:173-176

114. Thomassin-Nagarra I, Daraï E, Cuenod CA, Fournier L, Toussaint I, Marsault C, Bazot M (2009) Contribution of diffusion-weighted
MR imaging for predicting benignity of complex adnexal masses. Eur Radiol 19(6):1544-1552

115. Einarsdóttir H, Karlsson M, Wejde J, Bauer HCF (2004) Diffusion-weighted MRI of soft-tissue tumours. Eur Radiol 14 (6):959-963

116. Maeda M, Matsumine A, Kato H, Kusuzaki K, Maier SE, Uchida A, Takeda K (2007) Soft-tissue tumors evaluated by line-scan diffusion-weighted imaging: influence of myxoid matrix on the apparent diffusion coefficient. J Magn Reson Imaging 25(6):1199 1204

117. Nagata S, Nishimura $H$, Uchida $M$, Sakoda J, Tonan T, Hiraoka K, Nagata K, Akiba J, Abe T, Hayabuchi N (2008) Diffusionweighted imaging of soft-tissue tumors: usefulness of the apparent diffusion coefficient for differential diagnosis. Radiat Med 26 (5):287-295

118. Oka K, Yakushiji T, Sato H, Yorimitsu S, Hayashida Y, Yamashita Y, Mizuta H (2008) Ability of diffusion-weighted imaging for the differential diagnosis between chronic expanding haematomas and malignant soft tissue tumors. J Magn Reson Imaging 28 (5):1195-1200

119. Oka K, Yakushiji T, Sato H, Fujimoto T, Hirai T, Yamashita Y, Mizuta H (2011) Usefulness of diffusion-weighted imaging for differentiating between desmoid tumors and malignant soft tissue tumors. J Magn Res Imaging 33:189-193

120. Van Rijswijk CSP, Kunz P, Hogendoorn PCW, Taminiau AHM, Doornbos J, Bloem JL (2002) Diffusion-weighted MRI in the characterization of soft-tissue tumors. J Magn Res Imaging 15 (3):302-307

121. Thoeny HC, De Keyzer F (2007) Extracranial applications of diffusionweighted magnetic resonance imaging. Eur Radiol 17:1385-1393

122. Provenzale JM, Mukundan S, Barboriak DP (2006) Diffusion weighted and perfusion MR imaging for brain tumor characterization and assessment of treatment response. Radiology 239:632-649

123. Ebisu T, Tanaka C, Umeda M, Kitamura M, Naruse S, Higuchi T, Ueda S, Sato H (1996) Discrimination of brain abscess from necrotic or cystic tumors by diffusion-weighted echo planar imaging. Magn Reson Imaging 14(9):1113-1116

124. Buadu LD, Murakami J, Murayama S, Hashiguchi N, Sakai S, Masuda K, Toyoshima S, Kuroki S, Ohno S (1996) Breast lesions: correlation of contrast medium enhancement patterns on MR images with histopathologic findings and tumor angiogenesis. Radiology 200:639-649

125. Whiting PF, Weswood ME, Rutjes AW, Reitsma JB, Bossuyt PN, Kleijnen J (2006) Evaluation of QUADAS, a tool for the quality assessment of diagnostic accuracy studies. BMC Med Res Methodol 6:9

126. Abdel Razek AAK, Gaballa G, Denewer A, Tawakol I (2010) Diffusion-weighted MR imaging of the breast. Acad Radiol 17 (3):382-386

127. Padhani AR, Liu G, Mu-Koh D, Chenevert TL, Thoeny HC, Takahara T, Dzik-Jurasz A, Ross BD, van Cauteren M, Collins D, Hammoud DA, Rustin GJS, Taouli B, Choyke PL (2009) Diffusionweighted magnetic resonance imaging as a cancer biomarker: consensus and recommendations. Neoplasia 11(2):102-125

128. Bossuyt PM, Reltsma JB, Bruns DE, Gatsonis CA, Glasziou PP, Irwig LM, Lijmer JG, Moher D, Rennle D, de Vet HCW (2003) Towards complete and accurate reporting of studies of diagnostic accuracy: the STARD initiative. Radiology 226:24-28 